\title{
Advances in Laboratory-Scale Hydraulic Fracturing Experiments
}

\author{
Yelin Qian, ${ }^{1,2}$ Panpan Guo $\mathbb{D}^{2},{ }^{2}$ Yixian Wang $\mathbb{D}^{2},{ }^{2}$ Yanlin Zhao, ${ }^{3}$ Hang Lin, ${ }^{4}$ and Yan Liu ${ }^{5}$ \\ ${ }^{1}$ School of Management, Hefei University of Technology, Hefei 230009, China \\ ${ }^{2}$ School of Civil Engineering, Hefei University of Technology, Hefei 230009, China \\ ${ }^{3}$ School of Energy and Safety Engineering, Hunan University of Science and Technology, Xiangtan 411201, China \\ ${ }^{4}$ School of Resources and Safety Engineering, Central South University, Changsha 410083, China \\ ${ }^{5}$ State Key Laboratory of Explosion Science and Technology (Beijing Institute of Technology), Beijing 100081, China
}

Correspondence should be addressed to Panpan Guo; pp_guo@zju.edu.cn and Yixian Wang; wangyixian2012@hfut.edu.cn

Received 6 January 2020; Revised 14 June 2020; Accepted 30 June 2020; Published 29 July 2020

Academic Editor: Junhui Zhang

Copyright (c) 2020 Yelin Qian et al. This is an open access article distributed under the Creative Commons Attribution License, which permits unrestricted use, distribution, and reproduction in any medium, provided the original work is properly cited.

Hydraulic fracturing has been widely applied to stimulate the natural gas and oil production from unconventional reservoirs. To optimize the design of hydraulic fracturing in this application, an accurate estimation of the initiation and propagation of hydraulic fractures is indispensable. However, it still remains challenging as a result of the complex stress state and geological conditions. On account of their ability to complete control some significant factors and efficient observation of fracture geometry, laboratory-scale hydraulic fracturing experiments have received abundant research attention in recent years. This paper presents a review of the state of the art of laboratory-scale hydraulic fracturing experiments, focusing on the scaling analysis, experimental setup, fracturing fluids, and sample preparation. A discussion of the directions for future research is also provided with the intention of stimulating the development of the experimental technique for investigating hydraulic fracturing.

\section{Introduction}

The term "hydraulic fracturing" indicates the process of fracturing rock formations by pumping water-based fluids into the wellbore at a sufficiently high rate. This process is a rather complicated physical phenomenon coupling solid mechanics with multiphase fluid mechanics. Despite the complexity of the mechanism involved, the technique of hydraulic fracturing has been widely accepted by petroleum engineers since the first fracturing experiment conducted by Stanolind Oil in 1947. A specific feature that makes hydraulic fracturing attractive in petroleum engineering is that this technique allows both efficient and economical extraction of oil and gas from unconventional reservoirs such as shale formations, tight sands, and coal beds. In addition to stimulating oil and gas production, hydraulic fracturing technique has also been used in various other applications including mainly in situ stress measurement, water well development, block cave mining, enhanced geothermal energy, carbon sequestration, and tunnel and dam construction [1-5].
In the development of hydraulic fracturing technique, significant advances have been achieved recently. The rise of concern about the optimized design and better control of hydraulic fracturing treatment as well as the related environmental, health, and safety issues stimulate a variety of researches into hydraulic fracturing [6-9]. It is inevitable that the basic research field is the hydraulically fracture initiation and propagation mechanism, which is susceptible to many factors such as preexisting fractures (Figure 1(d)), horizontal stress difference, pump rate, fluid viscosity, and temperature. To better understanding of the initiation and propagation mechanism for hydraulic fractures, considerable effort has been made of theoretical models, numerical analyses, field tests, and laboratory experiments.

The theoretical models for hydraulic fracturing in the literature are abundant and of diverse complexity. They can be classified into the following four categories: (1) two-dimensional (2D) models (e.g., PKN model [11], KGD model [12], and penny-shaped model [13]), (2) pseudo three-dimensional (P3D) models (e.g., cell-based model [14] and lumped parameter model [15]), and (3) three-dimensional 

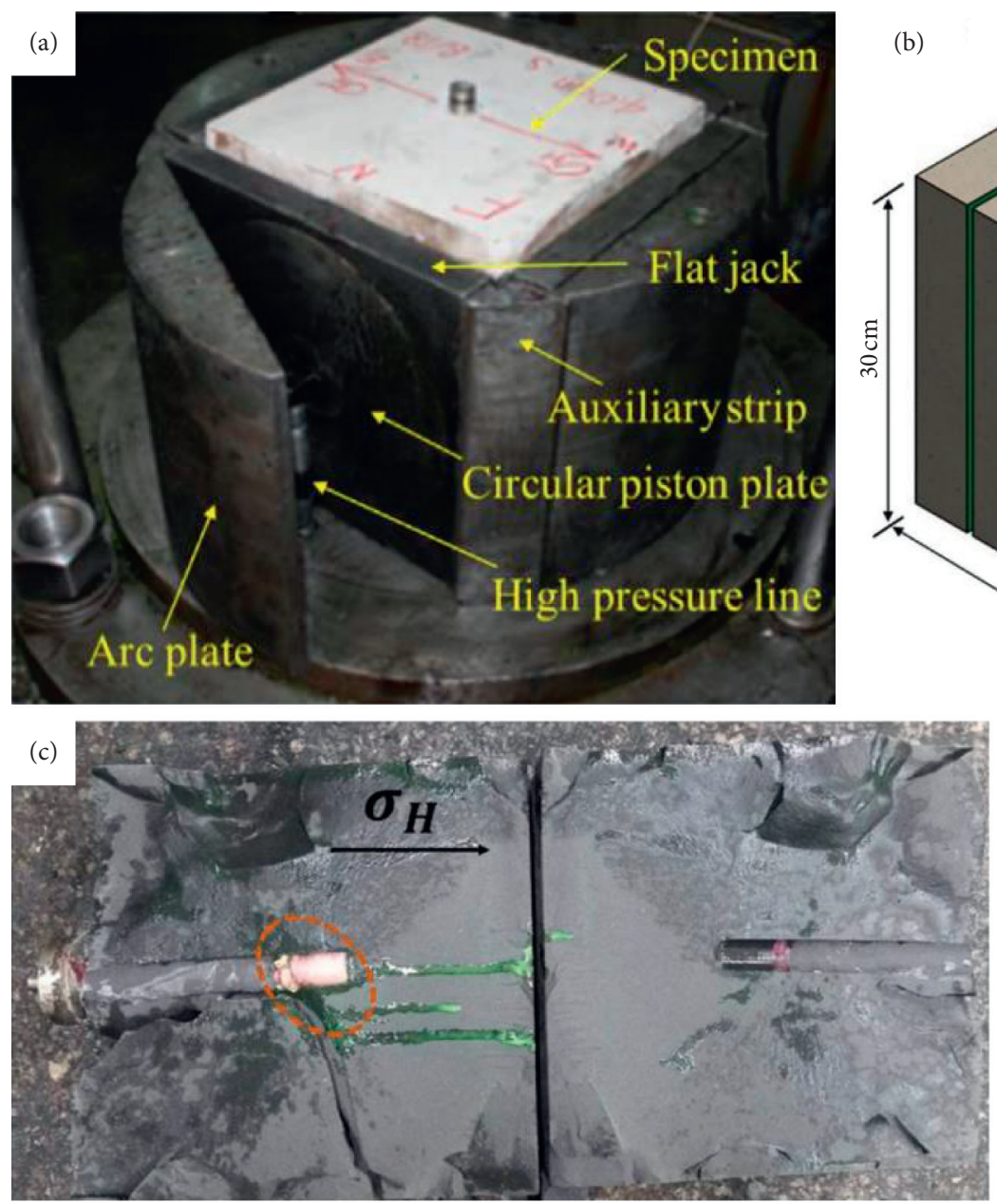
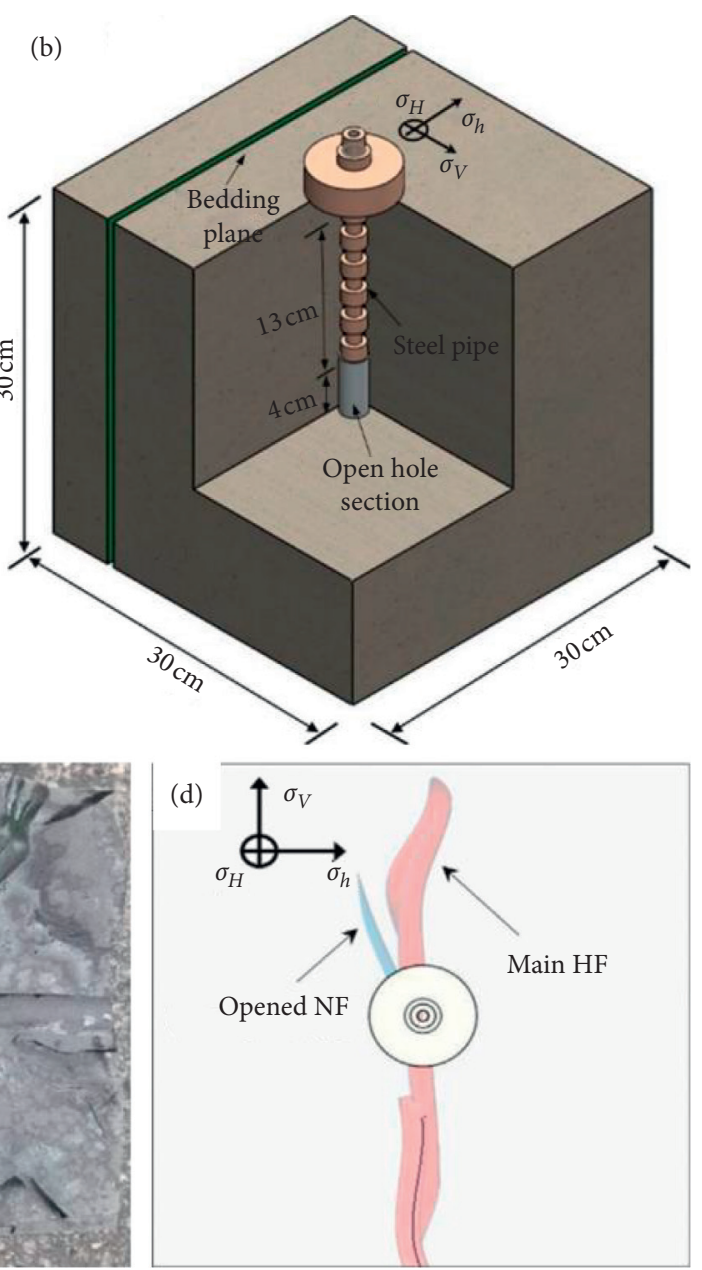

Figure 1: A laboratory-scale hydraulic fracturing experiment [10]. (a) True triaxial test stand. (b) Schematic of sample and wellbore. (c) Sample after hydraulic fracturing. (d) Schematic of main hydraulic fracture (HF) and opened natural fracture (NF).

(3D) planar models [16]. However, these theoretical models are not widely used in applications as they are incapable of reproducing the $3 \mathrm{D}$ nature of hydraulic fractures and do not account for the near-wellbore effects and the interaction between natural and hydraulic fractures $[17,18]$.

Numerical analyses of hydraulic fracturing have been frequently performed based on a variety of methods. Typical examples are the finite element method (FEM) [19], extended finite element method (XFEM) [20], distinct element method (DEM) [21], displacement discontinuity method (DDM) [22], rigid block spring method (RBSM) [23], 3D coupled hydromechanical XFEM [24], cohesive zone method (CZM) [25], and peridynamics [26]. The FEM assumes the domain of the hydraulic fracturing problem to be a continuum. The XFEM captures the fractures by employing enrichment functions introducing the jumps into the displacement field, which avoids remeshing during fracture propagation. The DEM represents the hydraulic fractures with broken bonds between neighboring discrete blocks, which allows the modelling of preexisting discontinuities such as joints, beddings, and cracks. The DDM is an implicit version of the DEM. The RBSM is similar to the DDM in view of the computational scheme and can be regarded as a discrete approach. The $3 \mathrm{D}$ coupled hydromechanical XFEM takes account of the hydromechanical coupling by adopting the generalized Biot theory and the lubrication equation. The CZM is based on the Khristianovitch hypothesis and overcomes the defects of the Griffith brittle fracture theory. The peridynamics, as a nonlocal continuum mechanics theory, can account for the growth of nonplanar, multiple fractures in an arbitrarily heterogeneous reservoir. An in-depth discussion of these numerical analysis methods can be found in the literature [27-29]. From the discussion, it is indicated that the numerical analysis methods still have great difficulty in tackling the heterogeneity of fractured reservoir and in capturing the real time stress variation during fracturing.

Field tests are a reliable method for investigating the initiation and propagation behavior of hydraulic fractures. The hydraulic fracturing behavior in a field test can be evaluated by methods of pressure-transient analysis, tracer analysis, flowback chemical analysis, and microseismic analysis $[18,30,31]$. However, in a field test, it is almost impossible to establish the cause of a high fracturing pressure due to the strong coupling among fluid flow, fracture opening, and fracturing at the tip as well as the 
incapacity to observe the fracture geometry [32]. As an alternative, laboratory experiment is capable of capturing the coupling of the three physical processes in fracture propagation and allow for convenient observation of the fracture geometry [33-36]. Additionally, they are of better controls of stress and boundary conditions and preexisting fractures, easy to operate, and cost effective [37-41]. Because of this, a variety of laboratory-scale hydraulic fracturing experiments have been performed, providing valuable information for calibration and verification of the theoretical and numerical models.

In recent years, significant progress has been made in the technique of laboratory-scale hydraulic fracturing experiments. Testing facilities of diverse features have been developed and used to study hydraulic fracturing behavior under various conditions. However, a survey of this issue, which is beneficial to the development and application of the hydraulic fracturing technique, is not available at present in the literature. Therefore, the objective of this study is to summarize the recent advances in laboratory-scale hydraulic fracturing experiments and discuss the directions for future research.

\section{Scaling Analysis}

Design of laboratory-scale hydraulic fracturing experiments capable of capturing similar phenomena to that expected at the field-scale tests requires consideration of the scaling laws that are intrinsic to the mathematical model [42]. However, a review of the reported experiments indicates that some of them have neglected the scaling laws, making it difficult to extrapolate the experimental results to field observations. For example, in the laboratory-scale hydraulic fracturing experiments by Lamont and Jessen [43], Kumari et al. [44], and Lin et al. [45], water having a relatively low viscosity was used as the fracturing fluid, indicating that the scaling laws were not fully satisfied. Moreover, the possibility exists that the results of the laboratory-scale hydraulic fracturing experiments without correct scaling of the physical phenomena bear no useful relation to field-scale hydraulic fractures [32]. To achieve a stable fracture propagation which is representative of the case in the field, in any experiment the relation among the different physical processes needs to be maintained by correct scaling.

The scaling laws for planar fracture propagation have been established by de Pater et al. [32] based on the derivation of the dimensionless products for the time of the experiment $N_{t}$, crack formation $N_{\Gamma}$, elastic deformation $N_{E}$, fluid leakoff $N_{K_{l}}$, and confining stress $N_{\sigma_{c}}$. These dimensionless products have the following forms:

$$
\begin{aligned}
& N_{t}=\frac{i}{r_{w}^{3}} t, \\
& N_{\Gamma}=\frac{4\left(1-v^{2}\right)}{E r_{w}} \Gamma, \\
& N_{E}=\frac{r_{w}^{3}}{48 i \mu\left(1-v^{2}\right)} E,
\end{aligned}
$$

$$
\begin{aligned}
& N_{K_{l}}=\sqrt{\frac{r_{w}}{i}} K_{l}, \\
& N_{\sigma_{c}}=\frac{4\left(1-v^{2}\right)}{E} \sigma_{c},
\end{aligned}
$$

where $i=$ fluid injection rate; $r_{w}=$ wellbore radius; $t=$ time; $E=$ Young's modulus; $\nu=$ Poisson's ratio; $\Gamma=$ separation energy; $\mu$ =viscosity; $K_{l}=$ leakoff $\quad$ coefficient; $\quad$ and $\sigma_{c}=$ confining stress.

By equating the dimensionless products defined in equations (1) to (5) under field condition to that under laboratory condition, the scale factors used for experiment design can be computed. It is shown that a proper laboratory-scale hydraulic fracturing experiment can be performed only if the used rock-like material is of low fracture toughness, low permeability, and high fluid viscosity. The fluid viscosity, total fracture propagation time, and injection rate are the three required parameters for experimental design, which can be obtained from the scaling analysis with inputs of sample size, wellbore size, field condition, and sample hydromechanical properties [46, 47]. A combination of high fluid viscosity and low injection rate is indispensable to capture the variation of fracture propagation regime from toughness-dominated to viscous-dominated in the field. It also plays an important role in controlling the fracturing mechanism and reducing the boundary effect [48, 49]. Nevertheless, the scaling analysis regarding three-dimensional fracture propagation has not been highlighted, and more related research work is therefore imperative.

\section{Experimental Setup}

A competent experimental setup is necessary for performing successful laboratory-scale hydraulic fracturing experiments. Since the initiation and propagation of hydraulic fractures is heavily dependent on the stress condition [50], the experimental set is expected to be capable of reproducing the in situ three-dimensional stress state. Meanwhile, limitations of the capability of an experimental setup may exist as a result of insufficient manufacturing ability or research financing. Given the circumstances, a variety of experimental setup has been developed for simulating hydraulic fracturing in laboratories. They can be classified into three categories according to the loading mode: (1) uniaxial type, (2) biaxial type, and (3) true triaxial type.

3.1. Uniaxial Type. The uniaxial experimental setup applies stress to a sample in only one direction (e.g., axial direction), which may induce a random propagation of hydraulic fractures within a plane perpendicular to the loading direction. The early applications of this type of experimental setup are, for example, to investigate hydraulic fracture propagation in layered formations [51] and to evaluate the frictional effects of unbonded interfaces on hydraulic fracture growth [52]. Recently, a more advanced test setup was developed, being capable of applying simultaneously a vertical load and a hydraulic pressure in preexisting fractures 
[53-55]. Moreover, various accessories such as transducers [56], high-resolution optical images [10], and acoustic emission (AE) sensors [57] can be added to the uniaxial type of experimental setup to facilitate mapping of hydraulic fractures.

Photos of the uniaxial type setup and measurements for hydraulic fracturing experiments used by some researchers are presented in Figure 2. The uniaxial type setup used by Daneshy [51], as presented in Figure 2(a), has the advantages of well control of fracture propagation speed and convenient observation of the fracture and the fluid during testing. The maximum magnitude of the load that can be applied on the samples is about $1379 \mathrm{kPa}$. In addition, during tests, the plots of fluid pressure variations versus the injection volume can be recorded, giving a rough measure of the development of fracture length. However, the uniaxial type setup used by Daneshy [51] is unable to monitor the initiation and propagation of hydraulic fractures. The initiation and propagation of hydraulic fractures can be monitored using the uniaxial type setup (Figure 2(b)) described in AlTammar et al. [10], as this setup is equipped with a $4 \mathrm{~K}$ resolution digital video camera. Being equipped with a specially designed water pressure device, the uniaxial type setup described in Gonçalves da Silva et al. [53] allows the application of hydraulic pressure to both natural and artificial fractures. This feature is not available in the above-discussed two experimental setups. In addition to this, eight acoustic emission sensors have been attached to the specimens tested by the uniaxial type setup described in Gonçalves da Silva et al. [53]. An example of the acoustic emission sensors is presented in Figure 2(f). In the uniaxial type experimental setup described by Moreno et al. [56], sixteen transducers were used to record the seismic waveforms. The recorded seismic waveforms can be used to extract the frequency content and fracture mechanisms. In the uniaxial type experimental setup reported in Anderson [52], an O-ring was glued to the bottom of the steel injection tube. This O-ring prevents the movement of the pressurized fracturing fluid to the surface of the borehole. Moreover, a $0.5 \mathrm{~mm}$ thin sheet was placed between the press platen and the specimen to reduce the friction between the press platen and the specimen and to distribute the load uniformly.

3.2. Biaxial Type. The biaxial experimental setup applies axial and radial stresses on a sample. It is also known as pseudo-triaxial test apparatus since two of the three principle stresses are equivalent. In general, a biaxial experimental setup consists of at least three subsystems, namely, confinement subsystem, loading subsystem, and fluid injection subsystem $[29,58]$. An additional subsystem, i.e., heating subsystem, may be also incorporated into a biaxial experimental setup for simulating the high ambient temperature in the deep rock formations $[44,59,60]$. The developed biaxial experimental setup in the literature varies, depending on several important technical parameters. These parameters include maximum axial pressure/load (e.g., $1000 \mathrm{MPa}$ [59] and $1000 \mathrm{kN}$ [44]), maximum confining pressure (e.g., $20 \mathrm{MPa}$ [61], $100 \mathrm{MPa}$ [62], and $137 \mathrm{MPa}$
[44]), maximum pore pressure (e.g., $100 \mathrm{MPa}$ [59]), maximum temperature (e.g., $100^{\circ} \mathrm{C}[60], 200^{\circ} \mathrm{C}[62]$, and $300^{\circ} \mathrm{C}$ [44]), and maximum fluid injection pressure (e.g., $35 \mathrm{MPa}$ [63] and $165 \mathrm{MPa}$ [44]). Similarly, a biaxial experimental setup may be also fitted out with AE sensors, deformation sensors, pressure sensors, high-speed cameras, etc.

Figure 3 presents the schematic diagrams and photos of some of the biaxial type setups for hydraulic fracturing experiments available in the literature. The biaxial type setup depicted in Figure 3(a) has an ability to apply confining and axial stresses up to $35 \mathrm{MPa}$. The dimension of the cylindrical sample tested by the biaxial type setup in Figure 3(a) is $2.5 \mathrm{~cm}$ in diameter and $5.0 \mathrm{~cm}$ in length. The porous disks placed at the two ends of the sample, as shown in Figure 3(a), are used to inject fluid into the sample. A photo of the hydraulic fracturing system in the biaxial type setup depicted in Figure 3(a) is shown in Figure 3(b). By using a PVC rubber jacket, the platens in the hydraulic fracturing system and the sample are isolated from the confining fluid. Moreover, acoustic emission and PZT sensor are incorporated into the biaxial type setup in Figure 3(a). Figure 3(c) depicts the interior of the apparatus for hydraulic fracturing experiments reported in Kumari et al. [44]. As can be seen in Figure 3(c), that silicon oil was used as the confining fluid, allowing for a maximum confining pressure of $137 \mathrm{MPa}$ which is significantly greater than the maximum confining pressure (i.e., $35 \mathrm{MPa}$ ) for the biaxial type setup in Wang et al. [64]. Moreover, an annealed copper sleeve, rather than a PVC rubber jacket used in the above-discussed biaxial type setup (Figure 3(a)), has been used for the isolation of the sample from the confining fluid. In addition, the specially designed steel clamps attached to the top and bottom pedestals as shown in Figure 3(c) can eliminate the fluid leakage. In the biaxial type setup depicted in Figure 3(d), the installation of O-rings between the sample and the nozzle plates prevents the fluid and pressure leakage during testing. The pressure sensors measure the injection fluid pressure, confining pressure, and vertical pressure. The biaxial type setup presented in Figure 3(e) is capable of testing large-size sample which is $100 \mathrm{~mm}$ in diameter and $200 \mathrm{~mm}$ in length. The monitoring system of this biaxial type setup is composed of the injection pressure control interface, acoustic emission system, and pressure sensors. The biaxial type setup presented in Figure 3(f) consists of an experimental platform, a computer control, a temperature control, and a servo loading subsystems. The maximum temperature attainable for this setup is $200^{\circ} \mathrm{C}$.

3.3. True Triaxial Type. The true triaxial experimental setup applies stresses of different magnitudes in three orthometric directions on a prismatic or cubic sample. This type of experimental setup is preferable to simulating hydraulic fracturing because of its ability to well reproduce the threedimensional stress state in an actual reservoir. The ability is empowered by the servo control subsystem of a true triaxial experimental setup which applies stresses on a sample with independent flat jacks (Figure 1(a)) driven by hydraulic cylinder $[18,66]$. The maximum applied stress attainable for 


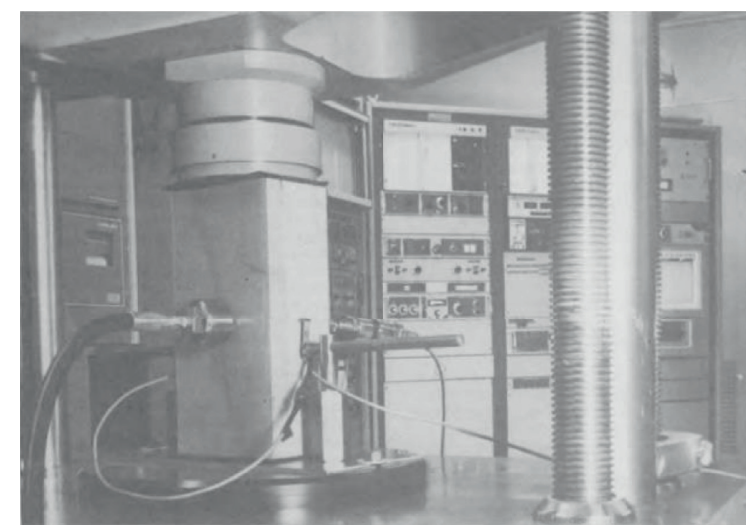

(a)

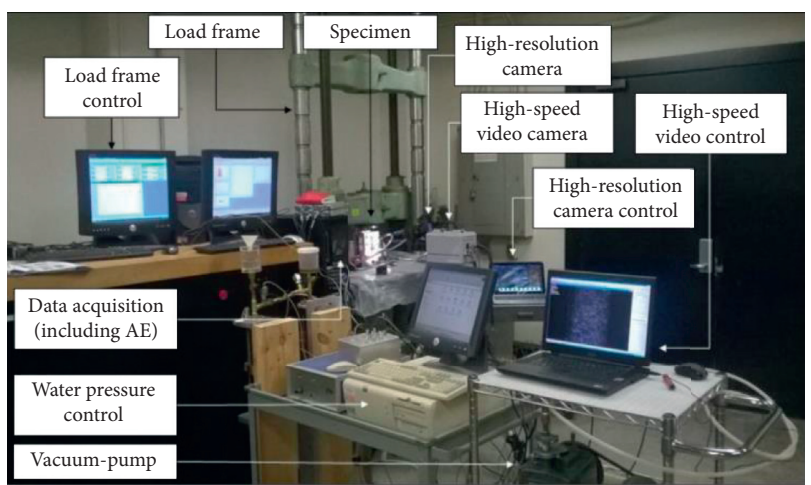

(c)

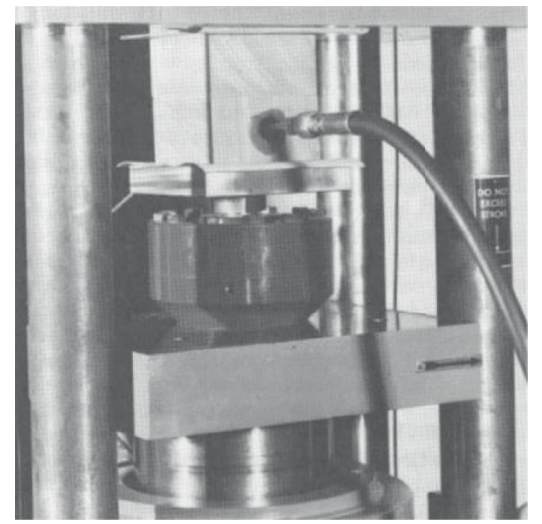

(e)

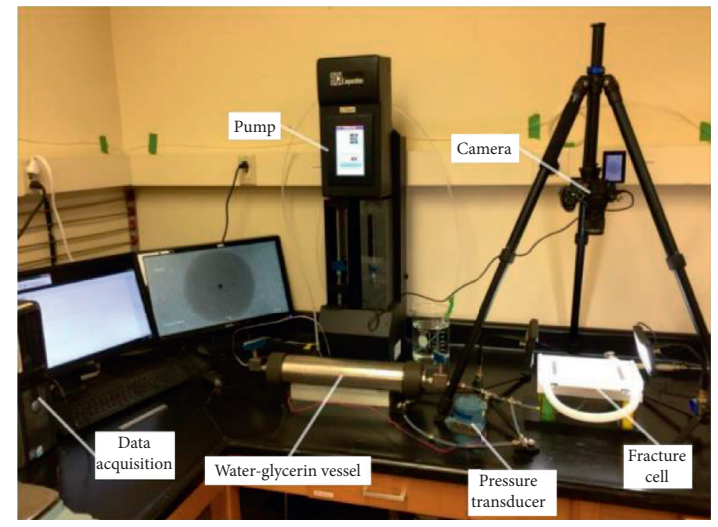

(b)

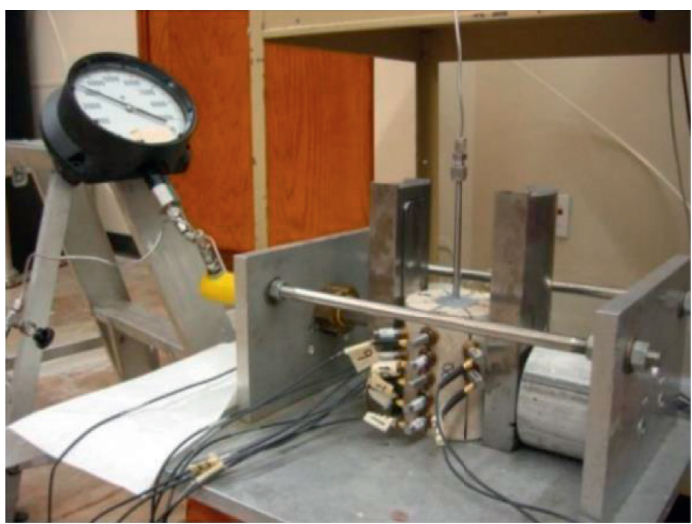

(d)

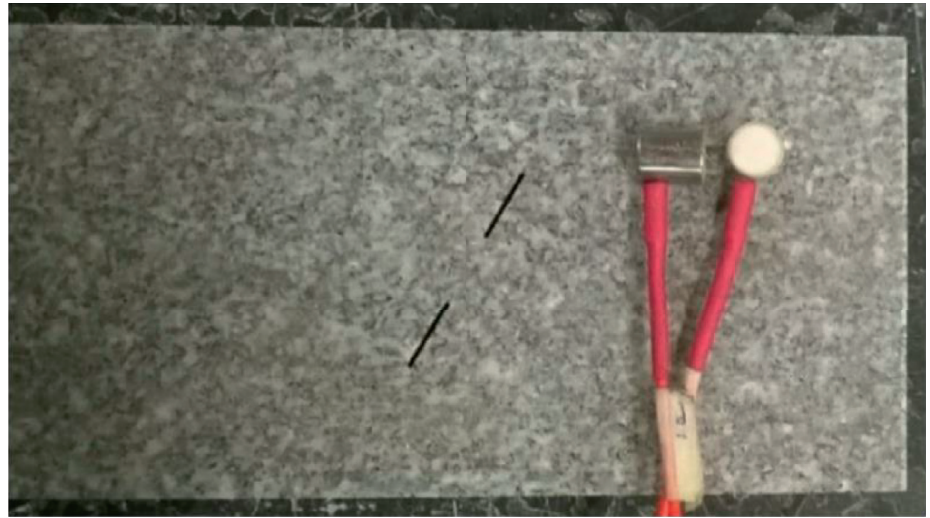

(f)

Figure 2: Uniaxial type setups for hydraulic fracturing experiments in (a) Daneshy [51]; (b) AlTammar et al. [10]; (c) Gonçalves da Silva et al. [53]; (d) Moreno et al. [56]; (e) Anderson [52]; and (f) Li et al. [55].

a true triaxial experimental setup is reported to be diverse, and it can be $28 \mathrm{MPa}$ [62], $30 \mathrm{MPa}$ [67], 39 MPa [68], $50 \mathrm{MPa}$ [69], $60 \mathrm{MPa}$ [70], etc. To achieve a uniform distribution of the applied stress on a sample face, four-square or spherical sheets are generally attached to the pressure platens $[49,71,72]$. Considering the possibility of the existence of shear stresses on a sample due to an error in sample dimension, Zhang and Fan [73] designed a flat jack with rational parts which is capable of eliminating the shear stresses. In addition, the insertion of a Vaseline-covered thin Teflon sheet between the pressure platen and sample has also been practiced to prevent the shear stress buildup $[74,75]$.

Some of the typical examples of true triaxial setups for hydraulic fracturing experiments are presented in Figure 4. The true triaxial setup presented in Figure 4(a) consists of five primary parts: true triaxial test stand, centrifugal pump, servo control system, data acquisition and processing system, and sand-mixing tank. For this setup, the maximum stress that can be applied using the flat jacks driven by hydraulic cylinder reaches $30 \mathrm{MPa}$. This maximum stress is lower than that for the true triaxial type setup presented in 


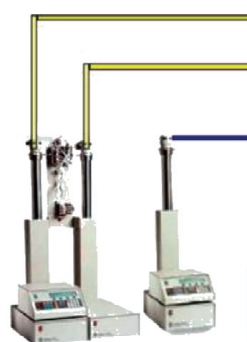

ISCO pumps

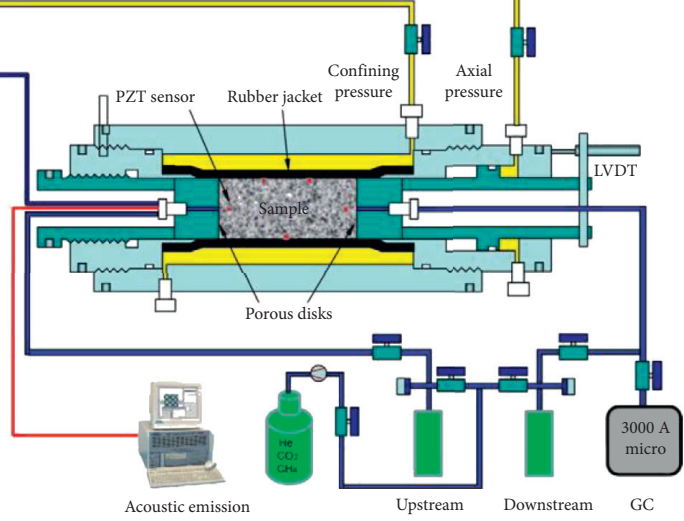

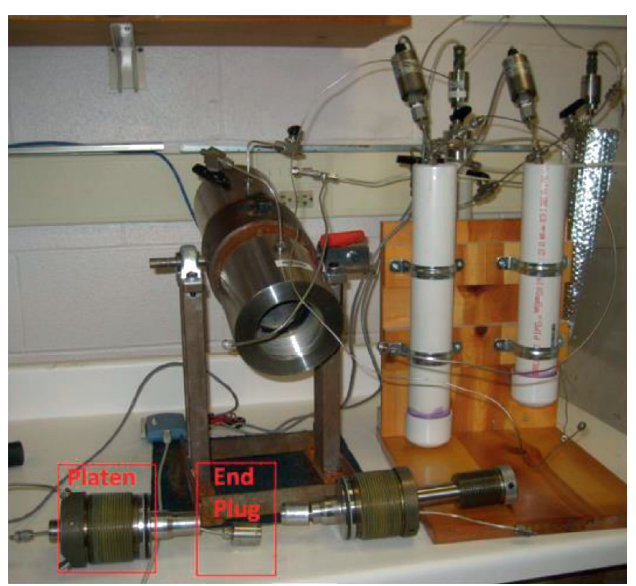

Valve

I Pressure transducer

• Air regulator

(a)

(b)

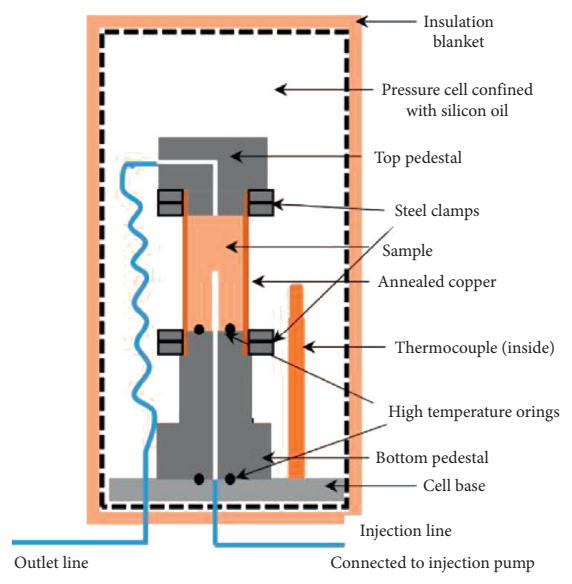

(c)

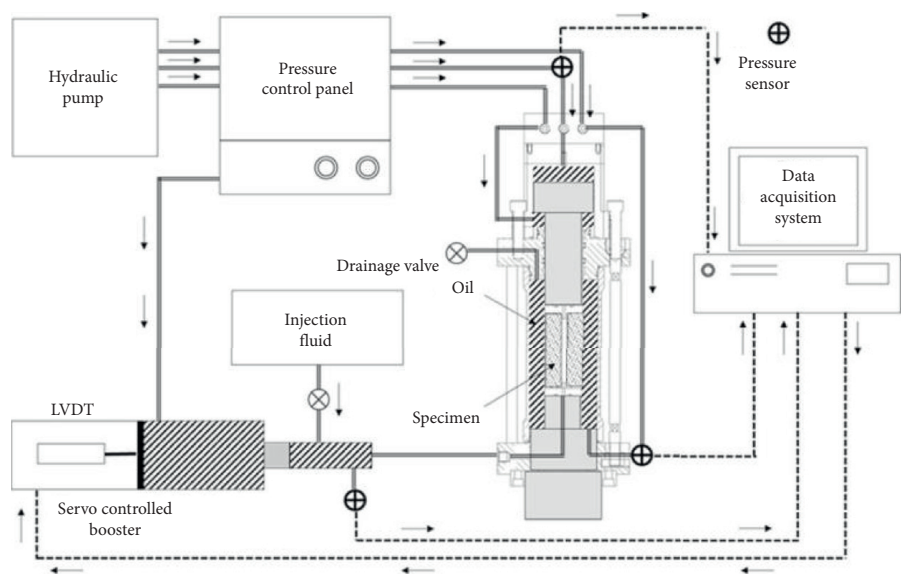

(d)

Figure 3: Continued. 

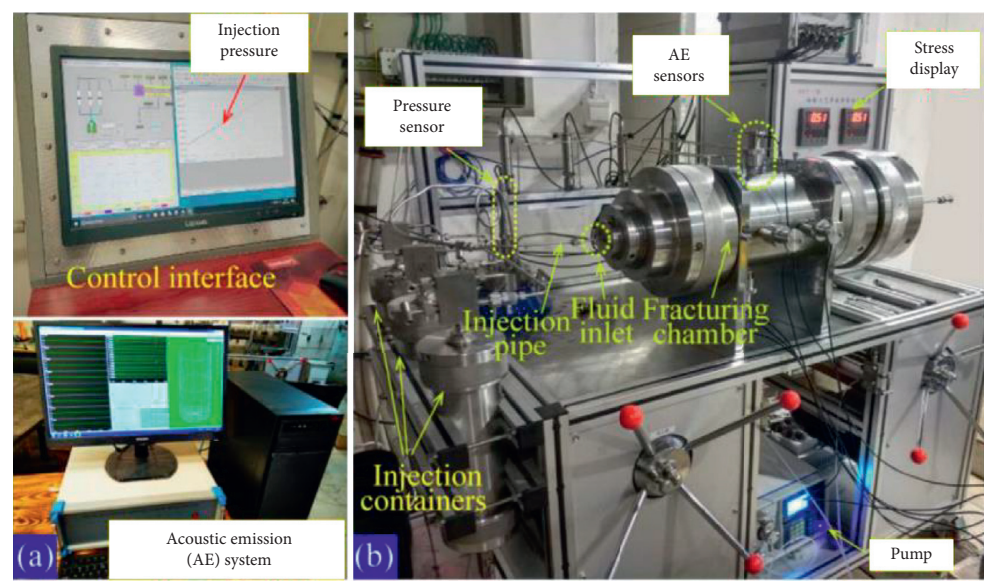

(e)

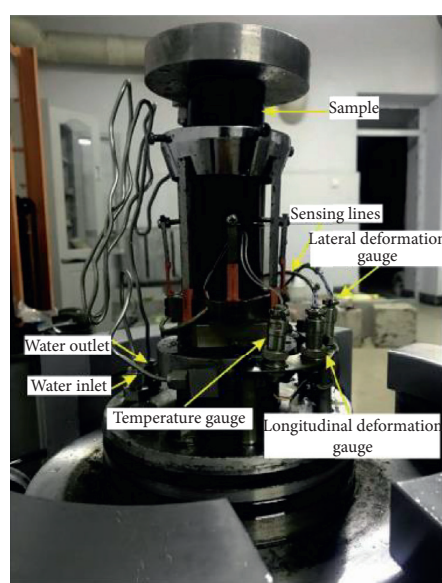

(f)

FIgURE 3: Biaxial type setups for hydraulic fracturing experiments in (a) Wang et al. [64]; (b) Li et al. [29]; (c) Kumari et al. [44]; (d) Zhuang et al. [61]; (e) Chen et al. [65]; and (f) Zhang et al. [59].

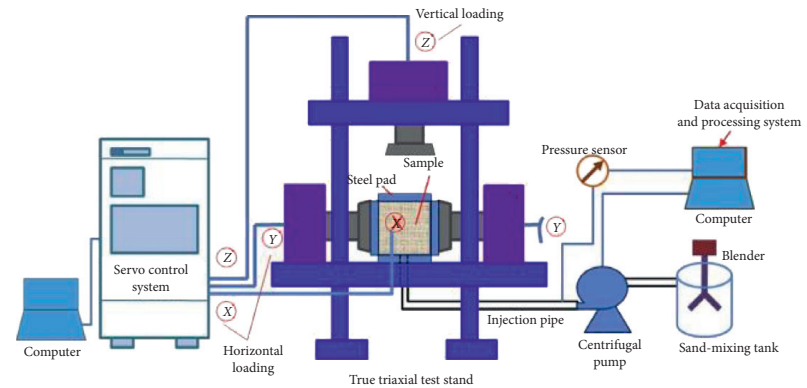

(a)

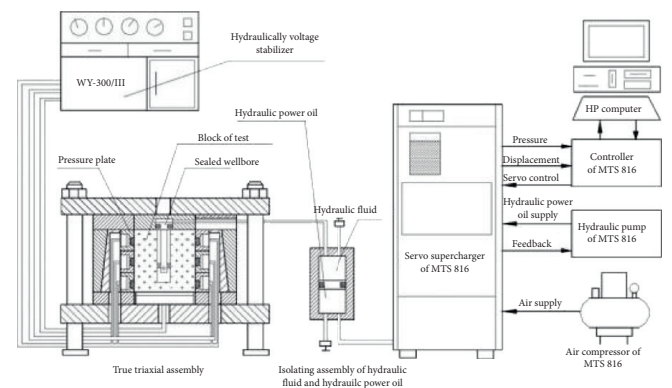

(c)

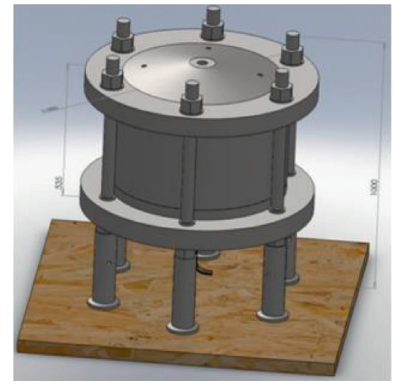

Cell assembly

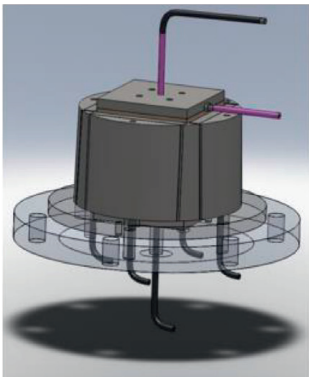

Main parts of assembly

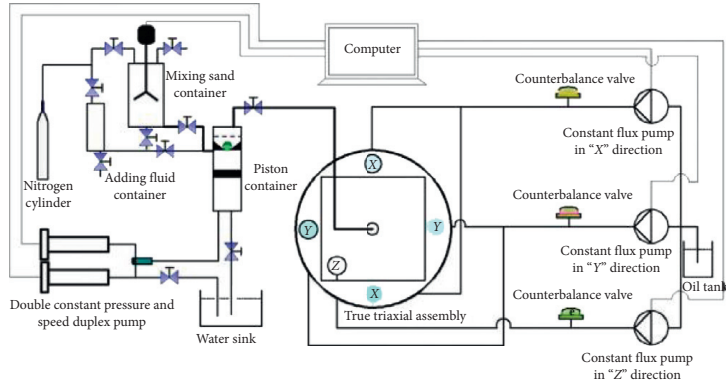

(b)

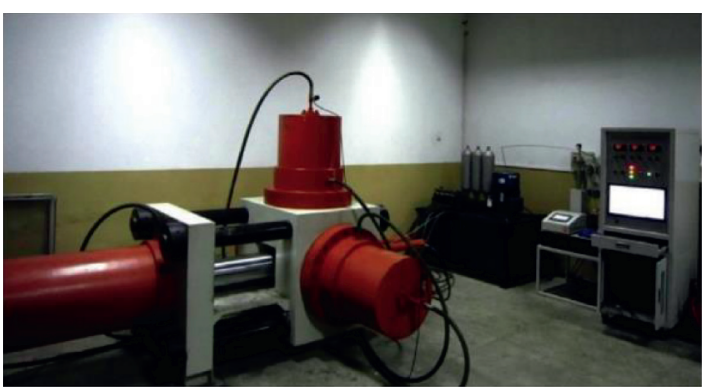

(d)

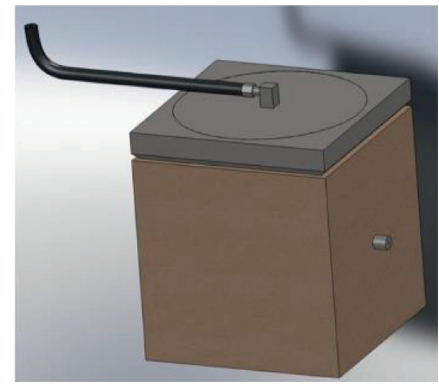

Flat jack assemblies

(e)

Figure 4: True triaxial type setups for hydraulic fracturing experiments in (a) Zhao et al. [18]; (b) Tan et al. [66]; (c) Zhang et al. [62]; (d) Guo et al. [69]; and (e) Zhang and Fan [73]. 
Figure 4(b). For the later, the pressing medium is silicone oil, and the maximum stress reaches $42 \mathrm{MPa}$. The true triaxial type setup presented in Figure 4(c) is composed of a true triaxial test frame, a fluid injection system, an MTS pressurization controller, and a data acquisition and processing system. The maximum stress that can be applied by the MTS pressurization controller is $28 \mathrm{MPa}$, which is lower than that for the true triaxial type setup shown in Figure 4(a). The maximum fluid injection pressure and the maximum fluid injection volume for the true triaxial type presented in Figure 4(c) are, respectively, $140 \mathrm{MPa}$ and $800 \mathrm{ml}$. Compared to conventional apparatus, the true triaxial type setup presented in Figure 4(d) has the advantage of conveniently installing and loading specimens. The maximum stress that can be applied by the stress loading system of the setup in Figure 4(d) reaches $50 \mathrm{MPa}$. The maximum fluid injection pressure is $70 \mathrm{MPa}$, which is only half of the maximum fluid injection pressure attained by the true triaxial type presented in Figure $4(\mathrm{c})$. The true triaxial type setup proposed by Zhang and Fan [73] can apply a stress on the sample up to $100 \mathrm{MPa}$. Moreover, this setup is capable of applying pore water pressure. The main assemblies of the true triaxial type setup proposed by Zhang and Fan [73] are presented in Figure 4(e). The cell assembly, which consists of more than 40 components, is $1.0 \mathrm{~m}$ in height and $0.8 \mathrm{~m}$ in diameter. The specially designed flat jack ensures a uniform distribution of the applied triaxial stresses on a sample, as it allows minor rotations between its stationary and moveable parts when the sample is imperfect. In addition, Zhang and Fan [73] suggested that the acoustic transducers are placed in the sample to ensure a better quality of acoustic emission signals. However, this can cause a greater stress concentration than placing the acoustic transducers in the metal flat jack. Moreover, this setup does not include a heating system and therefore cannot investigate the effect of temperature on hydraulic fracturing behavior. In this case, the application of the true triaxial type setup proposed by Zhang and Fan [73] is limited.

\section{Materials and Methods}

4.1. Fracturing Fluids. Fracturing fluids play crucial roles in a practical hydraulic fracturing application. They are injected into reservoir rock by pressurizing, with the objectives of creating fractures and keeping the created fractures open by proppants [7]. In a laboratory-scale hydraulic fracturing experiment, the selection of a proper fracturing fluid is indispensable to a full consideration of the scaling effect. According to the scaling laws, a proper fracturing fluid should be of very high viscosity considering the fact that the fluid injection rate in an experiment is relatively low. However, in many experiments the scaling effect has not been considered when selecting a fracturing fluid. Literature review indicates that a variety of fracturing fluids have been used in experiments. They include oil [76], water [77], guar gum [72], liquid carbon dioxide $\left(\mathrm{L}-\mathrm{CO}_{2}\right)$ [78], supercritical carbon dioxide $\left(\mathrm{SC}-\mathrm{CO}_{2}\right)$ [79], linear gel [80], polymer fluid [68], calcium chloride $\left(\mathrm{CaCl}_{2}\right)$ solution [81], methyl methacrylate (MMA) [57], nitrogen [10], and bentonite slurry [82]. Moreover, in an experiment, the fracturing fluid is often mixed with a fluorescent compound (Figure 1(c)) for better tracing of hydraulic fractures [83]. The fluorescent compound can be red ink [69] or dye of various colors such as red [84], green [85], blue [86], luminous yellow [66], and purple [77]. The commonly adopted fracturing fluids and their basic parameters as well as the medium used for tracing of hydraulic fractures are summarized in Table 1.

4.2. Sample Preparation. Sample preparation is one of the critical steps during the performance of a laboratory-scale hydraulic fracturing experiment. To prepare a sample, first, the material, geometry, and dimension need to be determined, followed by processing such as cutting, mixing, curing, drilling, and casing [88-92]. When selecting a sample material, the in situ reservoir formations are the preferences. However, technical difficulty and cost related problems may arise in extracting the in situ reservoir formations with a cover depth of several kilometers [93]. Therefore, in an experiment, outcrops, near-surface rocks, and artificial rocks are frequently used to prepare samples [50]. The sample geometry can be cylindrical, cubic, and of rectangular block, primarily depending on the type of the experimental setup. In general, the samples for a true triaxial experimental setup are cubic or of rectangular block, while cylindrical samples are frequently tested in a biaxial or uniaxial experimental setup. The selection of sample dimension is affected by several factors. In addition to falling within the scope of the experimental setup's capability, sample dimension should be sufficient to incorporate preexisting fractures and discontinuities [73], as well as avoiding the potential scaling effect $[94,95]$ and Poisson's effect [96]. A summary of the sample material, geometry, and dimension commonly used in true triaxial hydraulic fracturing tests is given in Table 2. Figure 5 presents the photos of the typical samples for hydraulic fracturing experiments which are made of, respectively, granite, mortar, shale, concrete, sandstone, coal, ice, carbonate, and limestone. For each of the sample pairs as shown in Figure 5, the photos presented above and below represent, respectively, the samples before and after hydraulic fracturing experiments.

To achieve the designed sample dimension, the outcrops of high-strength are directly cut using a cutting machine. For outcrops of low strength such as coal, a coating layer of cement is required after cutting $[66,111]$. The designed dimension of an artificial rock sample is achieved by pouring the mixture into a mould of specific dimension [112]. During this process, a steel tubing and papers can be embedded into the mixture to simulate, respectively, the wellbore and the preexisting fractures $[84,85]$. Generally, to ensure that the strength of an artificial rock sample is sufficient, a curing for a few days at proper temperature and humidity conditions is imperative [46]. Moreover, the wellbore can also be simulated by drilling the outcrop samples or the artificial rock samples on completion of curing and then inserting a prefabricated steel tubing into the drilled borehole (Figure 3(b)). In this case, a high-strength epoxy glue is needed to bind the wellbore and the sample [62]. 
TABLE 1: Summary of the commonly adopted fluids for laboratory-scale hydraulic fracturing experiments.

\begin{tabular}{|c|c|c|c|c|c|}
\hline Fluid & Viscosity & Flow rate $(\mathrm{ml} / \mathrm{min})$ & Setup type & Tracing medium & Reference \\
\hline Gear oil & $132 \mathrm{a}$ & 0.05 & True triaxial & NA & {$[76]$} \\
\hline Water & NA & 5 & Biaxial & Purple fluorescent dye & [77] \\
\hline Guar gum & $135 \mathrm{~b}$ & 0.252 & True triaxial & Red agent & {$[72]$} \\
\hline $\mathrm{L}-\mathrm{CO}_{2}$ & $0.1 \mathrm{~b}$ & 1 & Uniaxial & Resin-fluorescent substance mixture & {$[78]$} \\
\hline $\mathrm{x}$-linked guar & $35 \mathrm{~b}$ & 20 & True triaxial & Red tracer & {$[79]$} \\
\hline Linear gel & $65 \mathrm{~b}$ & 10 & True triaxial & Red ink & {$[80]$} \\
\hline Polymer & $0.5 \mathrm{~b}$ & 0.042 & True triaxial & Fluorescent dye & {$[68]$} \\
\hline $\mathrm{CaCl}_{2}$ solution & $1 \mathrm{~b}$ & 2 & True triaxial & Red dye & {$[81]$} \\
\hline MMA & $0.8 \mathrm{~b}$ & 2 & Uniaxial & Fluorescent compound & {$[57]$} \\
\hline Glycerin & $942 \mathrm{~b}$ & 15 & Uniaxial & NA & {$[10]$} \\
\hline Viscasil oil 500 & $0.6 \mathrm{~b}$ & 15 & Biaxial & NA & {$[82]$} \\
\hline Slick water & $3 b$ & 30 & True triaxial & Fluorescent tracer & [83] \\
\hline Slick water & $2.5 \mathrm{~b}$ & 100 & True triaxial & Red ink & [69] \\
\hline Clear water & $1 \mathrm{~b}$ & 20 & True triaxial & Red dye & {$[84]$} \\
\hline Guar gum & $135 \mathrm{~b}$ & 19.56 & True triaxial & Green dye & {$[85]$} \\
\hline Tellus 100 oil & $300 \mathrm{~b}$ & NA & True triaxial & Blue dye & {$[86]$} \\
\hline Silicone oil & $1000 \mathrm{c}$ & 30 & True triaxial & NA & {$[87]$} \\
\hline
\end{tabular}

Note. $\mathrm{a}=\mathrm{mm}^{2} / \mathrm{s} ; \mathrm{b}=\mathrm{MPa} \cdot \mathrm{s} ; \mathrm{c}=\mathrm{cSt} ; \mathrm{NA}=$ not available.

TABLE 2: Samples used for laboratory-scale hydraulic fracturing experiments with a true triaxial experimental setup.

\begin{tabular}{lcccc}
\hline Material & Mechanical parameter ${ }^{1}$ & Geometry $^{2}$ & Dimension $^{3}$ & References $^{2}$ \\
\hline Granite & $(67.91,0.31) ;(38-43,0.2-0.3) ;(65,0.27)$ & RB; cube & $15^{2} \times 25 ; 17^{3} ; 33^{3}$ & {$[76,81,97,98]$} \\
Mortar & $(27.74,0.19) ;(8.402,0.23) ;(7.43,0.15)$ & Cube & $10^{3} ; 15^{3} ; 30^{3}$ & {$[46,68,72,85,99,100]$} \\
Shale & $(32.44,0.23) ;(36.36,0.241) ;(37.18,0.236) ;$ & Cube & $10^{3} ; 30^{3} ; 40^{3}$ & {$[62,67,80,83,101-103]$} \\
Concrete & $(32.7,0.26) ;(14.06,0.367) ;(40,0.18)$ & RB & $30^{2} \times 60$ & {$[84]$} \\
Sandstone & $(24.6,0.17)$ & RB; cube & $30^{3} ; 76.2^{2} \times 91.44 ; 60 \times 30^{2}$ & {$[69,79,104-106]$} \\
Coal & $(23.6,0.218) ;(38.2,0.241)$ & Cube & $40^{3}$ & {$[66]$} \\
Cement & $(4.05,0.25)$ & Cube & $30^{3}$ & {$[49,86]$} \\
Ice & $(24,0.15)$ & Cube & $20^{3}$ & {$[107]$} \\
Hydrostone & $\mathrm{NA}$ & Cube & $30^{3}$ & {$[108]$} \\
Carbonate & $(7.86,0.2)$ & Cube & $30^{3}$ & {$[109]$} \\
Limestone & $\mathrm{NA}$ & Cube & $40^{3}$ & {$[110]$} \\
\hline
\end{tabular}

Note. ${ }^{1}$ The mechanical parameters are Young's modulus $(\mathrm{GPa})$ and Poisson's ratio. ${ }^{2} \mathrm{RB}=$ rectangular block. ${ }^{3}$ The dimension is presented in $\mathrm{cm}$.

\section{Discussion}

A discussion of the potential directions for future research into laboratory-scale hydraulic fracturing experiments is presented in this section. Laboratory-scale hydraulic fracturing experiments have provided valuable information about the behavior of hydraulic fractures under various effects. Nevertheless, it is still worth a discussion of the way to obtain a truer experimental result relative to the state of the art. The primary way is to narrow the gap between the real reservoir conditions and the simulated ones.

5.1. Temperature Effect. Among them, the temperature effect is essential but has not been well addressed up to now $[113,114]$. The ambient temperature in the real reservoir with a cover depth of 3700 to $7000 \mathrm{~m}$ is estimated to be approximately 100 to $180^{\circ} \mathrm{C}$. At this high temperature, the strength and failure mode of reservoir rocks differ from that at a relatively lower temperature, and this difference varies according to the type of reservoir rock. For example, with an increase in the temperature from 25 to $160^{\circ} \mathrm{C}$, the strength of fine sandstone increases while medium mudstone decreases [115]. In addition, the failure morphology of sandstone under triaxial compression varies according to the temperature. Figure 6 compares the failure morphologies of fine, medium, and argillaceous fine sandstones as well as of silty mudstones under triaxial compression at various temperatures. It can be indicated from Figure 6 that the length and the amount of the fractures increase with increasing the temperature. Figure 7 presents the injection pressure-time, breakdown pressure-time, and tensile strength-temperature curves for the Harcourt granite obtained by Kumari et al. [44]. It is clear that the temperature has an important effect on the hydraulic fracturing behavior and tensile strength of the Harcourt granite. In this way, the hydraulic fracturing behavior is dependent on the temperature. However, this effect has been only rarely investigated due to the restriction of experimental setup $[73,116]$. It was found that the difference between the hydraulic fracturing mechanisms at $300^{\circ} \mathrm{C}$ and at room temperature results from the thermally induced microcracks and changes in reservoir rock and 

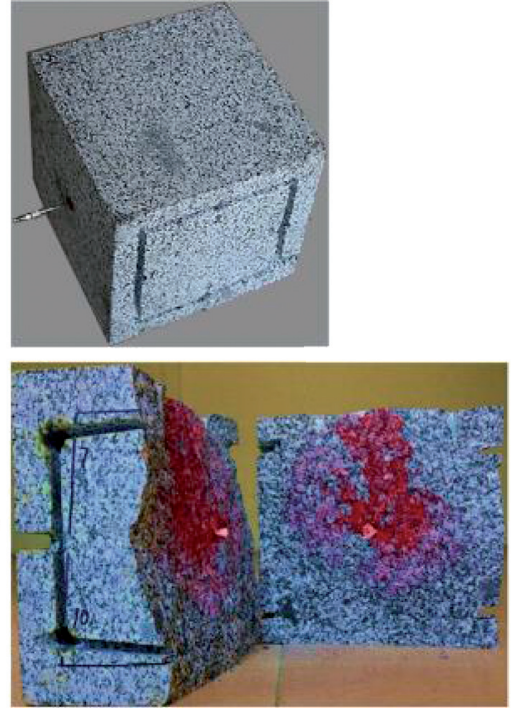

(a)
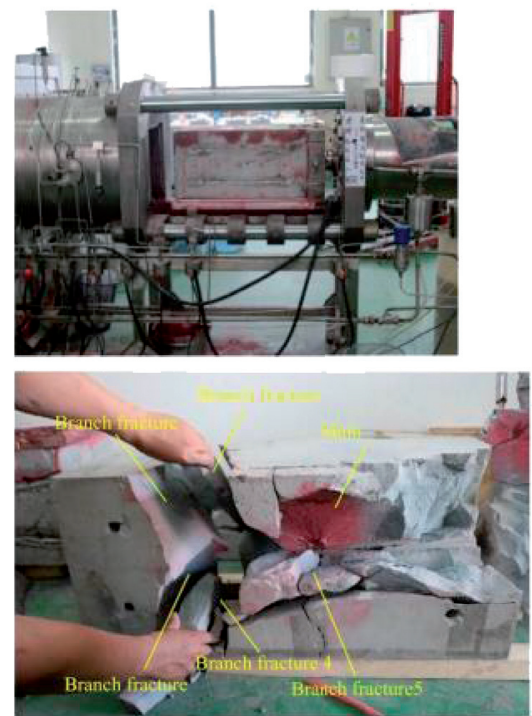

(d)
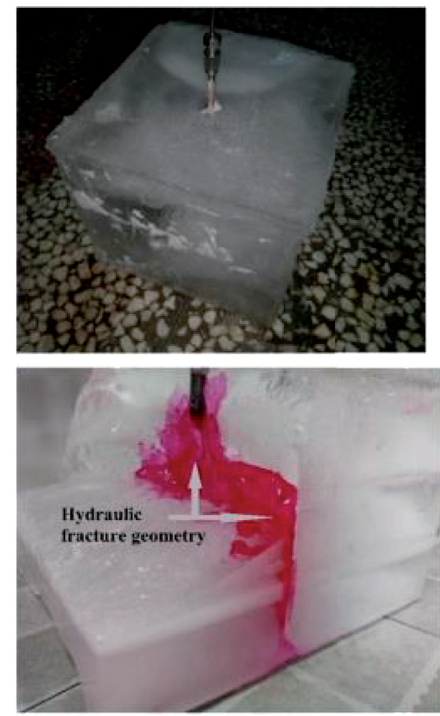

(g)
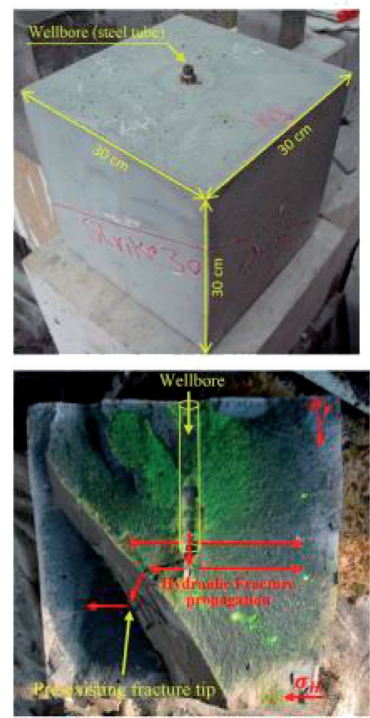

(b)
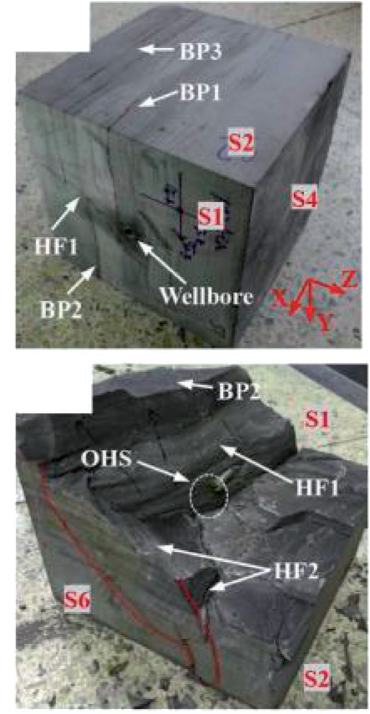

(e)
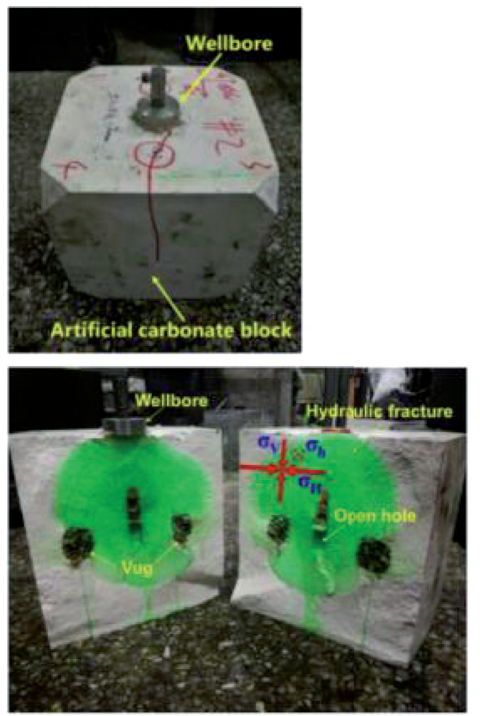

(h)
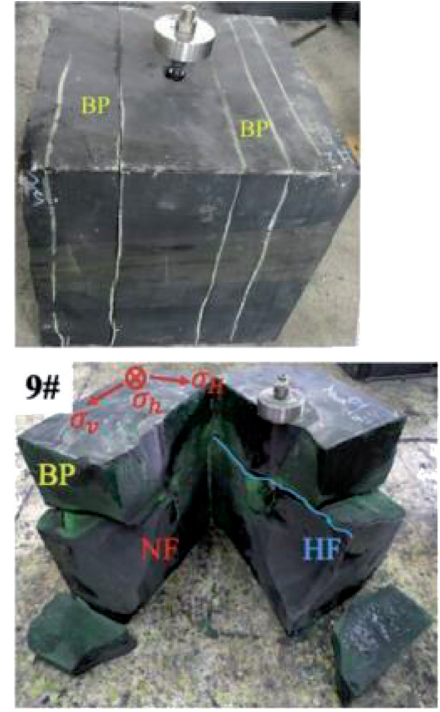

(c)
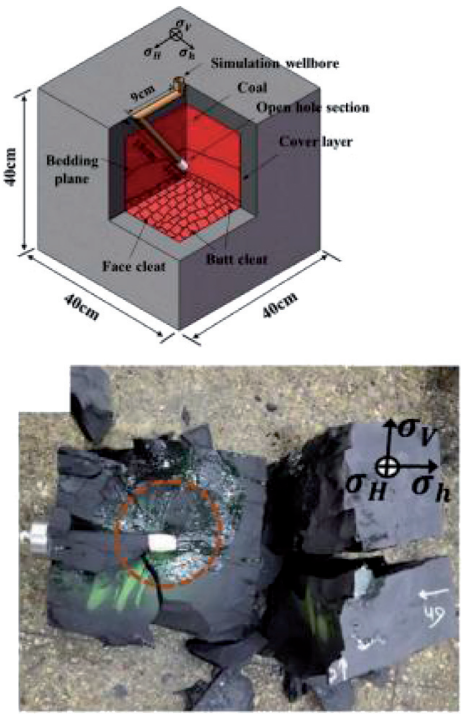

(f)
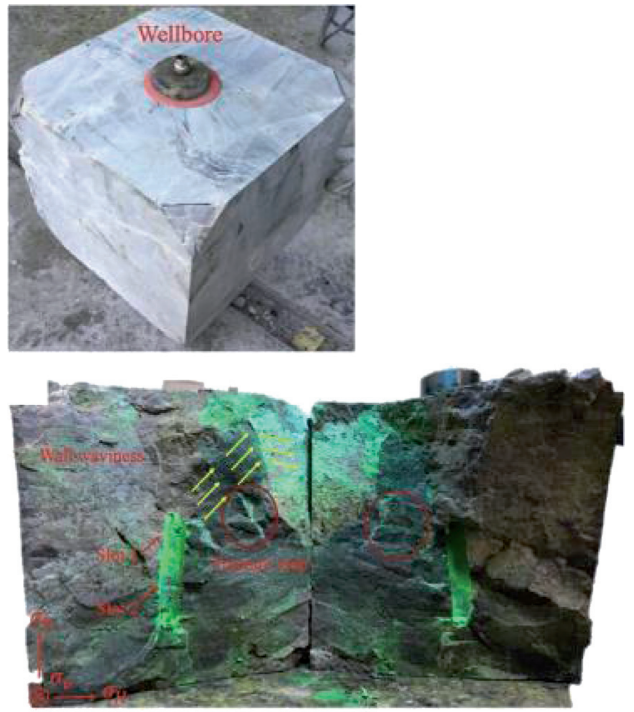

(i)

Figure 5: Photos of typical samples made of different materials before and after hydraulic fracturing experiments. (a) Granite [81]. (b) Mortar [85]. (c) Shale [62]. (d) Concrete [84]. (e) Sandstone [79]. (f) Coal [66]. (g) Ice [107]. (h) Carbonate [109]. (i) Limestone [110]. 


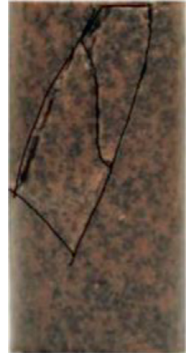

(a)

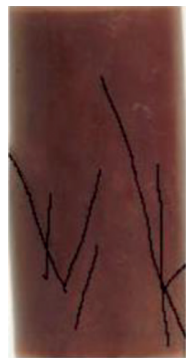

(f)

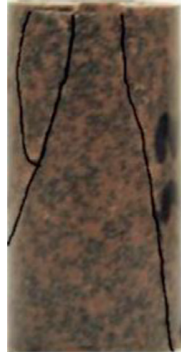

(b)

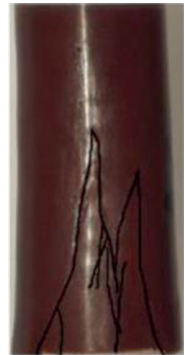

(g)

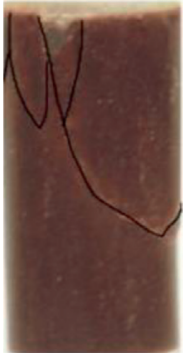

(c)

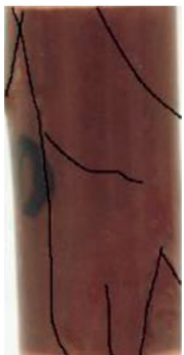

(h)

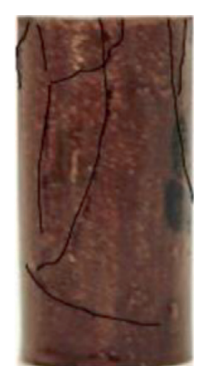

(d)

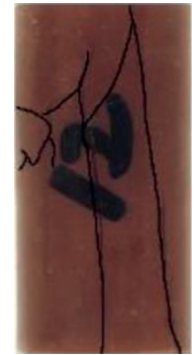

(i)

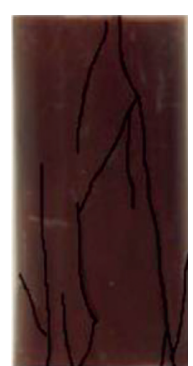

(e)

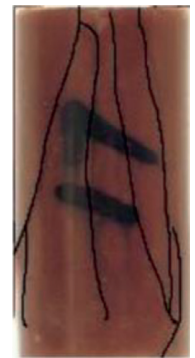

(j)

Figure 6: Temperature effect on the failure morphology of sandstone under triaxial compression [115]. (a) Fine sandstone at $25^{\circ} \mathrm{C}$. (b) Fine sandstone at $160^{\circ} \mathrm{C}$. (c) Medium sandstone at $25^{\circ} \mathrm{C}$. (d) Medium sandstone at $160^{\circ} \mathrm{C}$. (e) Argillaceous fine sandstone at $25^{\circ} \mathrm{C}$. (f) Argillaceous fine sandstone at $160^{\circ} \mathrm{C}$. (g) Silty mudstone at $25^{\circ} \mathrm{C}$. (h) Silty mudstone at $80^{\circ} \mathrm{C}$. (i) Silty mudstone at $120^{\circ} \mathrm{C}$. (j) Silty mudstone at $160^{\circ} \mathrm{C}$.

fracturing fluid properties [44]. However, the fracture geometry considering coupling of the temperature effect and the stress state effect still remains unclear and needs more experimental studies [81].

5.2. In Situ Stress Effect. An ideal laboratory-scale hydraulic fracturing experiment should reproduce the in situ stress condition in formation, as the in situ stress condition controls the initiation and propagation of hydraulic fractures. According to the in situ stress measurement using hydraulic fracturing at the Kamaishi iron mine [117], the in situ stress field is three-dimensional in nature, meaning that the three principal stresses are different in both direction and magnitude. The results of the mineback experiments conducted by Warpinski and Teufel [118] indicate that in a highstress region the in situ stress distribution has an overriding influence on hydraulic fracture containment. Beugelsdijk et al. [74] pointed out that the horizontal stress difference has an influence on the hydraulic fracture geometry. As presented in Figure 8, the hydraulic fracture interacts with the preexisting discontinuities when the horizontal stress difference is 0.25 (Figure 8(a)); however, when the horizontal stress difference is increased to 2.5 , the hydraulic fracture propagates in the direction of the preferred fracture plane (Figure 8(b)), regardless of the discontinuities encountered. Moreover, the horizontal stress difference affects the amount of the hydraulic fractures. The experimental results by Zhou et al. [119] indicate that the hydraulic fractures are, respectively, dominating fracture with multiple branches, partly vertical fracture with random branches and radial random net-fractures at the horizontal stress differences of 10,2 , and 1 . The photos of these fractures at various horizontal stress differences are presented in Figure 9. In addition, the in situ stress evolves in the hydraulic fracturing process due to stress distribution induced by the creation and propagation of hydraulic fractures. The evolving stress will affect the further propagation of the formerly created fractures, which leads to further change of the stress condition. Therefore, the stress condition and the fracture propagation are coupled. This coupling phenomenon has not been investigated, and the present experimental setups are unable to facilitate this investigation. At present, most of the available setups for hydraulic fracturing experiments are uniaxial and biaxial types, which cannot simulate the threedimensional stress state in a real reservoir. The available true triaxial type setups for hydraulic fracturing are generally capable of reproducing the in situ stress field but cannot take account of the coupling between the stress and the initiation and propagation of the fractures. Consequently, there is a clear need to devise a more advanced experimental setup accounting for the evolving of stress in a hydraulic fracturing process. Based on the advances in the capabilities of true triaxial type setups for hydraulic fracturing experiments, the potential directions for future research by experiments with respect to the in situ stress effect may be to (1) investigate the coupling between stress field and fluid viscosity or injection rate; (2) capture the effect of the wellbore direction relative to the principal stress direction; and (3) explore the sequential effect of multiple wellbore injection under different stress conditions.

5.3. Preexisting Fracture Effect. Preexisting fractures, such as natural flaws, bedding planes, joints, faults, and artificial discontinuities, can have a significant effect on the 


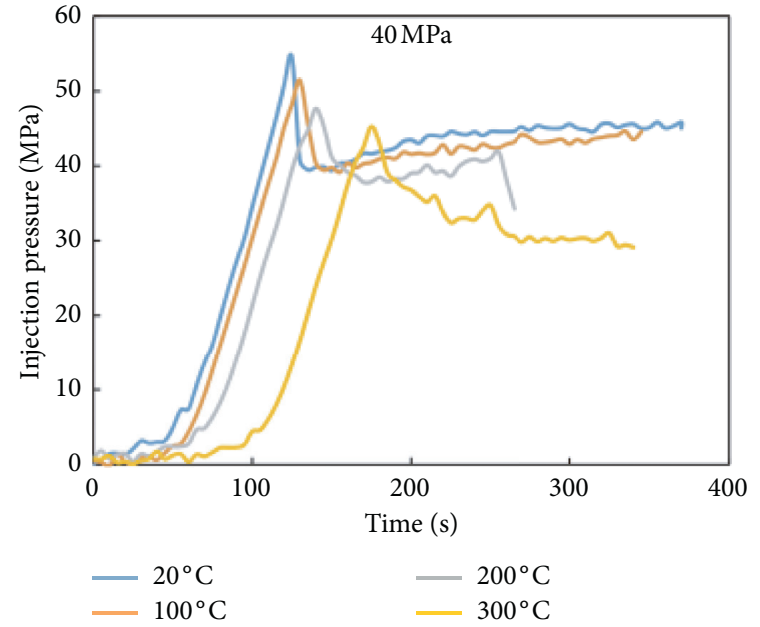

(a)

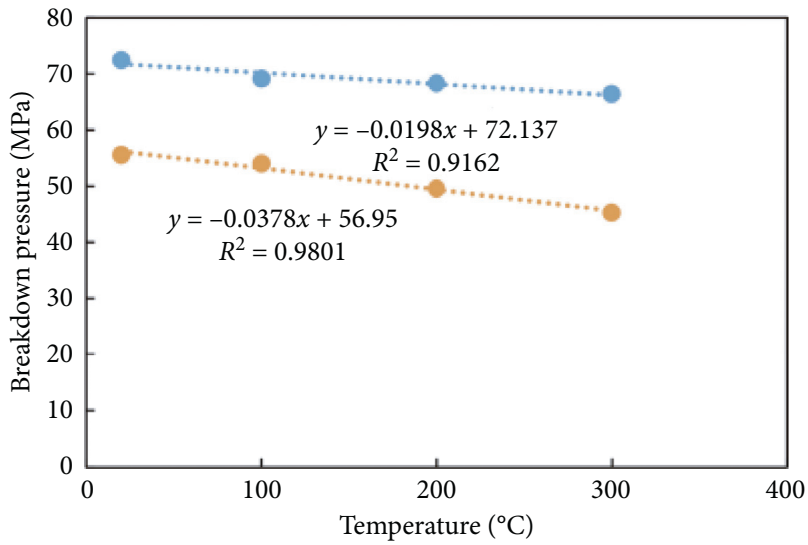

$60 \mathrm{MPa}$

- $40 \mathrm{MPa}$

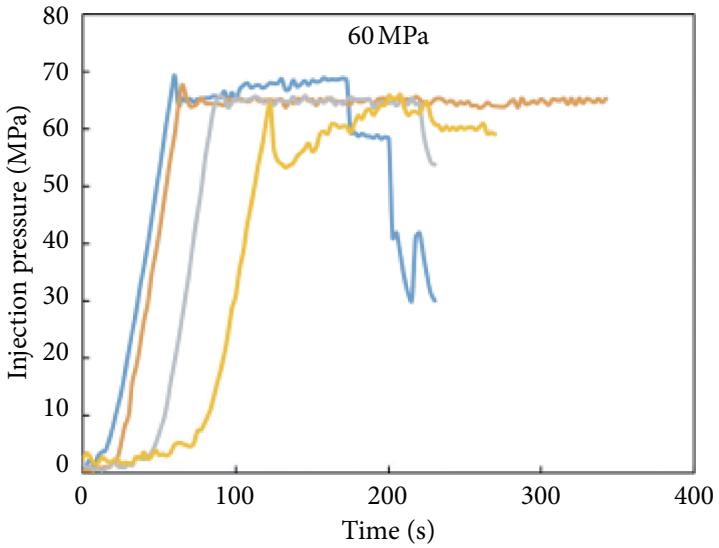

$-20^{\circ} \mathrm{C}$

$-200^{\circ} \mathrm{C}$

$-300^{\circ} \mathrm{C}$

(b)

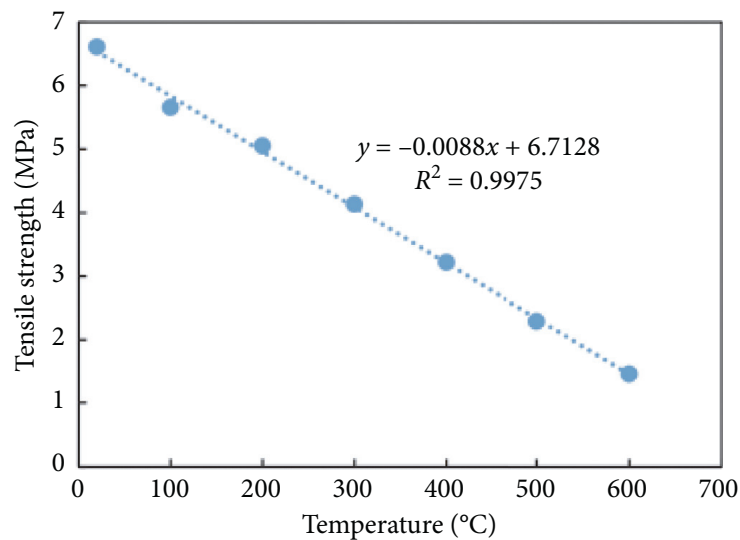

(d)

Figure 7: Temperature effect on the hydraulic fracturing behavior and tensile strength of Harcourt granite [44]. (a) Injection pressure-time curves at $40 \mathrm{MPa}$ confining pressure. (b) Injection-time curves at $60 \mathrm{MPa}$ confining pressure. (c) Breakdown pressure-temperature curves. (d) Tensile strength-temperature curve.

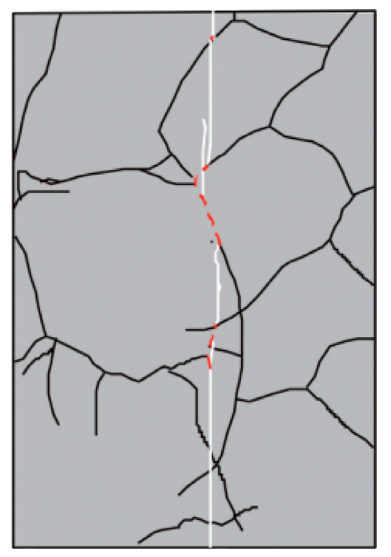

(a)

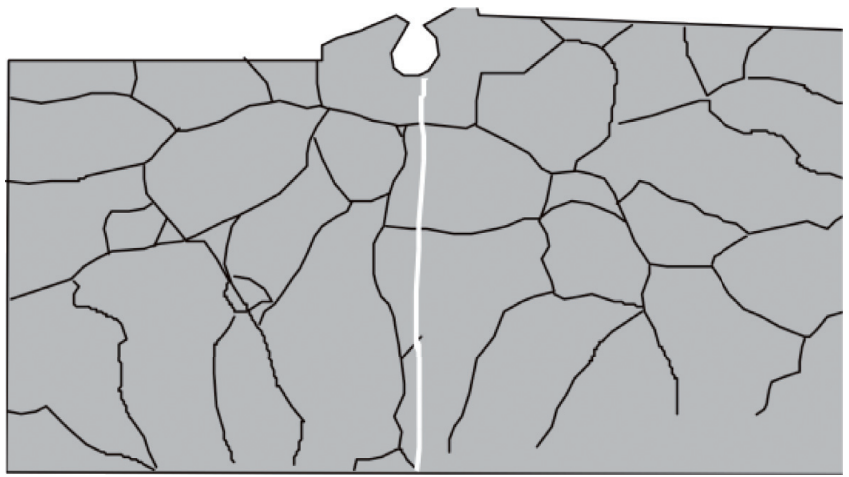

(b)

FIGURE 8: Schematic of the influence of horizontal stress difference on hydraulic fracture geometry [74]. (a) Horizontal stress difference $K_{h}=0.25$. (b) Horizontal stress difference $K_{h}=2.5\left(K_{h}=\left(\sigma_{y}-\sigma_{x}\right) / \sigma_{x}\right.$ where $\sigma_{x}$ and $\sigma_{y}$ are, respectively, the minimum and maximum horizontal principal stresses). 


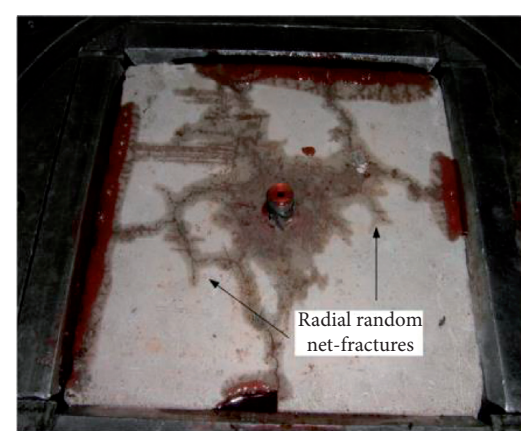

(a)

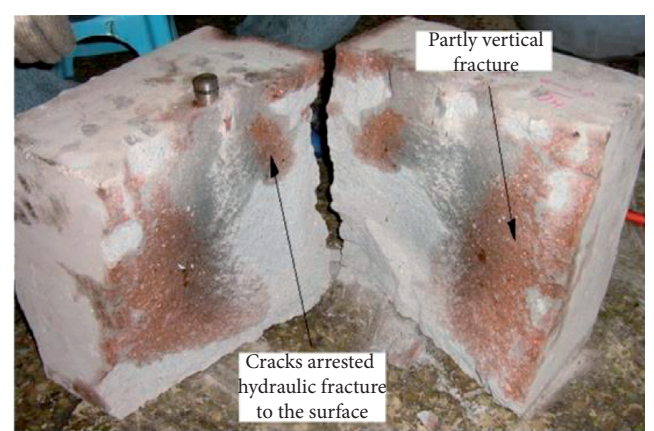

(b)

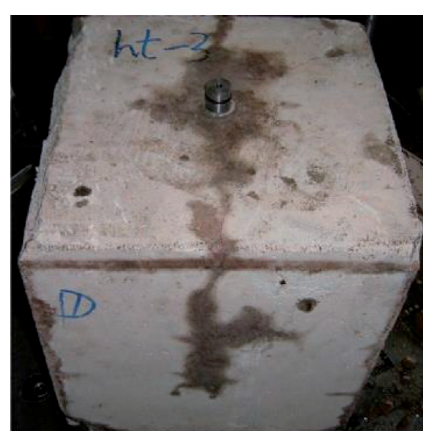

(c)

Figure 9: Photos of hydraulic fractures [119]. (a) Radial random net-fractures at the horizontal stress difference of 1 . (b) Partly vertical fracture with random branches at the horizontal stress difference of 2. (c) Dominating fracture with multiple branches at the horizontal stress difference of 10 .

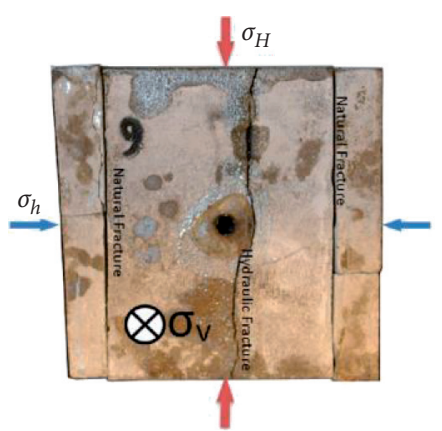

(a)

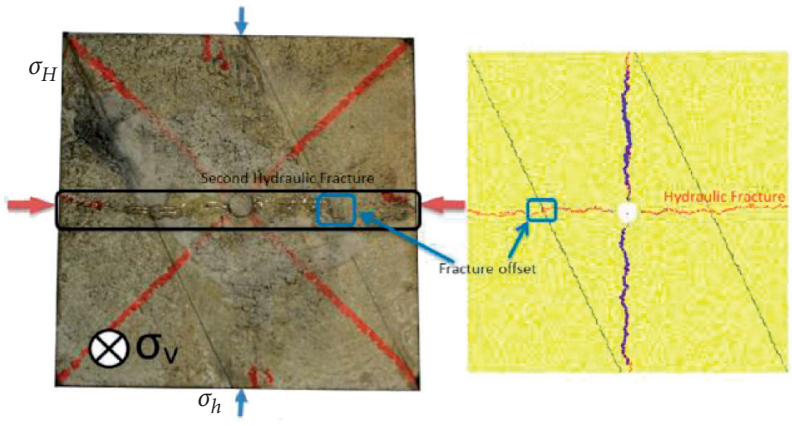

(c)

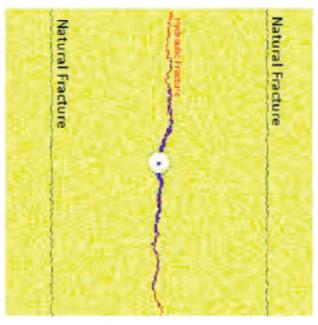

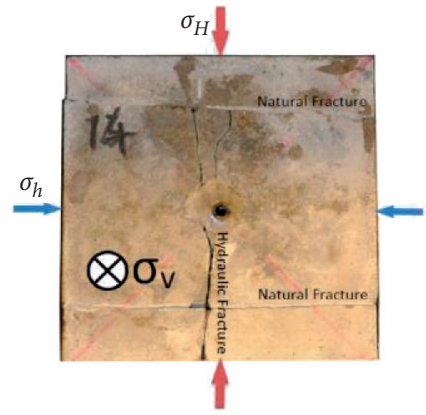

(b)

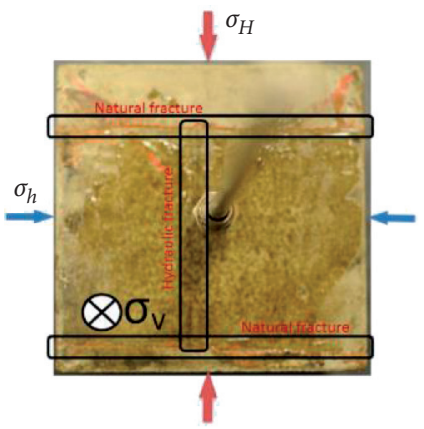

(d)
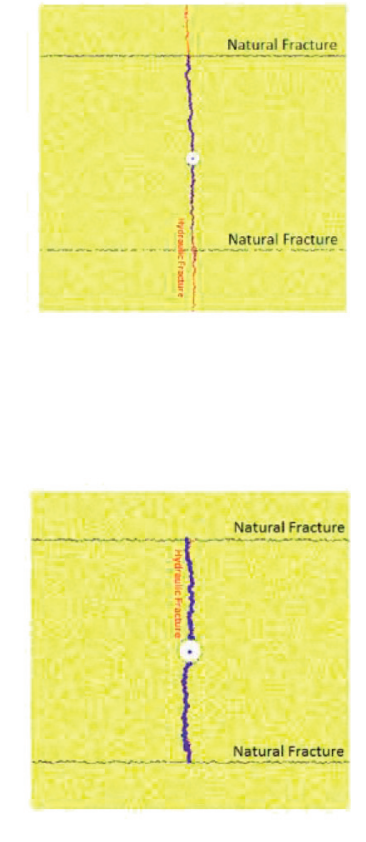

Figure 10: Photos and schematic of experimentally observed interaction forms between hydraulic fracture and preexisting fracture [48]. (a) No interaction. (b) Crossing without offset. (c) Crossing with offset. (d) Arrested.

propagation geometry and effectiveness of hydraulic fracture. The preexisting fracture effect can occur by increasing fluid leakoff, arresting the growth of the fracture, enhancing the initiation of multiple fractures, and hindering proppant transport [118]. When fracturing hydraulically a sample with preexisting fractures, interaction may occur or may not occur between the hydraulic fracture and the preexisting fracture. The interaction can be varied in form, depending on many factors such as horizontal stress difference, approach angle, fluid properties, injection rate and pressure, and approach angle [120]. The possible forms of the interaction include (1) hydraulic fracture crosses preexisting fracture without offset; (2) hydraulic fracture crosses preexisting fracture with offset; and (3) hydraulic fracture is arrested at preexisting fracture. The interaction of different forms between hydraulic fracture and preexisting fracture has been observed in experiments by Fatahi et al. [48], and some of the photos illustrating the forms of the interaction are presented in Figure 10. To get a better understanding of the mechanism of the interaction between hydraulic and preexisting fractures, experimental investigation has been performed on natural and artificial samples $[18,48,75,118,120]$. The use of a sample made of natural reservoir material in a hydraulic fracturing experiment takes account of the real distribution of the natural fracture and provides convenience, but the hidden natural fracture and the difference in the grain size can cause stress concentration which will alter the propagation of hydraulic fracture. 
Therefore, it is suggested that an artificial sample be adopted in a laboratory-scale hydraulic fracturing experiment, which will make sure that the synthetic fracture is the only heterogeneity in the sample. As for the method for creating a preexisting fracture in an artificial sample, the use of an oil coated galvanized steel plate and glue is usual $[47,48]$. In addition, slides of plaster [120], plate made of the same material to the sample [75], and servo-controlled drill rig [105] have also been employed to achieve this goal. However, it has to be pointed out that most of the experimental work investigating the interaction between preexisting and hydraulic fractures treats the preexisting fracture as a planar interface, meaning that the actual thickness of the preexisting fracture has been neglected. This treatment can yield an unreasonable experimental result as the actual preexisting fracture is three-dimensional in nature. Moreover, the filling material properties in the preexisting fracture and the interfacial shear strength between the filling material and the surrounding rock also has a significant effect on the interaction mechanism. These issues have not been well addressed so far, and thus further experimental research should be directed into these potential research topics.

\section{Conclusions}

Recent advances in laboratory-scale hydraulic fracturing experiments are significant. This paper presents a review of some of these advances to stimulate the development of the hydraulic fracturing technique. The review addresses the scaling analysis, experimental setup, materials, and methods. A discussion is also presented of the potential directions for future research with respect to laboratory-scale hydraulic fracturing experiments. The conclusions drawn from this study are summarized as follows:

(i) To ensure a stable fracture propagation representative of the real case, it is significant that the scaling laws are fully obeyed in the design of a laboratoryscale hydraulic fracturing experiment. The scaling laws require the sample fracture toughness and permeability to be low and the fluid viscosity to be high in magnitude for the case of a low injection rate adopted commonly in a laboratory-scale hydraulic fracturing experiment. The theoretical basis for the scaling of three-dimensional fracture propagation is of practical significance but has not been fully investigated.

(ii) A setup for hydraulic fracturing experiment is basically composed of loading subsystem, fluid injection subsystem and auxiliary subsystem. Considering the mode of the loading subsystem, the setups available in the literature can be classified into uniaxial type, biaxial type, and true triaxial type. The true triaxial type is preferable because it simulates the anisotropic 3D stress state in the field. For a better understanding of the hydraulic fracturing behavior under real conditions, the capabilities of the true triaxial type setups should be improved by, for example, (a) increasing the loading capacity; (b) incorporating the ability to apply pore water pressure and high temperature; (c) supplementing more advanced sensors and facilities to map the instantaneous propagation of hydraulic fractures; and (d) devising a special facility to store the monitoring sensors or proposing a new method for reducing the stress concentration effect caused by the placement of the monitoring sensors.

(iii) Among the factors affecting the creation and propagation behavior of a hydraulic fracture, the temperature, in situ stress, and preexisting fracture are the primary ones and should be taken into account in the performance of a well-designed hydraulic fracturing experiment. The temperature alters the mechanism of hydraulic fracturing by yielding microcracks in the reservoir rock and changing the fracturing fluid properties. The in situ stress evolves in the process of hydraulic fracturing, but this evolving phenomenon is unable to be accounted for due to the limitation of the capability of the present true triaxial type setups. The coupling between the in situ stress effect and the temperature effect as well as the effects of other important testing parameters can be investigated in the future to further the understanding of the complex hydraulic fracturing behavior. The preexisting fracture effect has not been well addressed in terms of the fracture width, fracture filling material properties, and interfacial shear strength between filling material and surrounding reservoir rock. These aspects should direct the future research into the behavior of hydraulic fracture by laboratory-scale experiments.

\section{Data Availability}

The data used to support the findings of this study are available from the corresponding author upon request.

\section{Conflicts of Interest}

The authors declare that they have no conflicts of interest.

\section{Acknowledgments}

This work was supported by the National Natural Science Foundation of China (51774107, 51774322, and 51774131), the Fundamental Research Funds for the Central Universities of China (JD2020JGPY0011), the State Key Laboratory of Explosion Science and Technology (Beijing Institute of Technology)(KFJJ19-02M), and the Hunan Provincial Natural Science Foundation of China (2018JJ2500).

\section{References}

[1] J. Adams and C. Rowe, "Differentiating applications of hydraulic fracturing," in Effective And Sustainable Hydraulic Fracturing, IntechOpen, London, UK, 2013.

[2] M. Kuriyagawa, H. Kobayashi, I. Matsunaga, T. Yamaguchi, and K. Hibiya, "Application of hydraulic fracturing to threedimensional in situ stress measurement," International 
Journal of Rock Mechanics and Mining Sciences \& Geomechanics Abstracts, vol. 26, no. 6, pp. 587-593, 1989.

[3] A. Li, F. Dai, N. Xu, G. Gu, and Z. Hu, "Analysis of a complex flexural toppling failure of large underground caverns in layered rock masses," Rock Mechanics and Rock Engineering, vol. 52, no. 9, pp. 3157-3181, 2019.

[4] B. Li, N. Xu, F. Dai, P. Xiao, and G. Zhang, "Dynamic analysis of rock mass deformation in large underground caverns considering microseismic data," International Journal of Rock Mechanics and Mining Sciences, vol. 122, p. 13, 2019.

[5] B. Li, T. Li, N. Xu, F. Dai, W. Chen, and Y. Tan, "Stability assessment of the left bank slope of the Baihetan Hydropower Station, southwest China," International Journal of Rock Mechanics and Mining Sciences, vol. 104, pp. 34-44, 2018.

[6] Q. Li, H. Xing, J. Liu, and X. Liu, "A review on hydraulic fracturing of unconventional reservoir," Petroleum, vol. 1, no. 1, pp. 8-15, 2015.

[7] R. Barati and J.-T. Liang, "A review of fracturing fluid systems used for hydraulic fracturing of oil and gas wells," Journal of Applied Polymer Science, vol. 131, no. 16, p. 11, 2014.

[8] M. S. H. M. Mehany and A. Guggemos, "A literature survey of the fracking economic and environmental implications in the United States," Procedia Engineering, vol. 118, pp. 169176, 2015.

[9] A. Vengosh, R. B. Jackson, N. Warner, T. H. Darrah, and A. Kondash, "A critical review of the risks to water resources from unconventional shale gas development and hydraulic fracturing in the United States," Environmental Science \& Technology, vol. 48, no. 15, pp. 8334-8348, 2014.

[10] M. J. AlTammar, D. Gala, M. M. Sharma, and J. McAndrew, "Laboratory visualization of fracture initiation and propagation using compressible and incompressible fracturing fluids," Journal of Natural Gas Science and Engineering, vol. 55, pp. 542-560, 2018.

[11] T. K. Perkins and L. R. Kern, "Widths of hydraulic fractures," Journal of Petroleum Technology, vol. 13, no. 9, pp. 937-949, 1961.

[12] J. Geertsma and F. De Klerk, "A rapid method of predicting width and extent of hydraulically induced fractures," Journal of Petroleum Technology, vol. 21, no. 12, pp. 1571-1581, 1969.

[13] S. H. Advani, J. S. Torok, J. K. Lee, and S. Choudhry, "Explicit time-dependent solutions and numerical evaluations for penny-shaped hydraulic fracture models," Journal of Geophysical Research, vol. 92, no. 8, pp. 8049-8055, 1987.

[14] E. R. Simonson, A. S. Abou-Sayed, and R. J. Clifton, "Containment of massive hydraulic fractures," Society of Petroleum Engineers Journal, vol. 18, no. 1, pp. 27-32, 1978.

[15] M. P. Cleary, M. Kavvadas, and K. Y. Lam, "Development of a fully three-dimensional simulator for analysis and design of hydraulic fracturing," in Proceedings of the SPE/DOE Low Permeability Gas Reservoirs Symposium, Society of Petroleum Engineers of AIME, Denver, CO, USA, 1983.

[16] S. H. Advani, T. S. Lee, and J. K. Lee, "Three-dimensional modeling of hydraulic fractures in layered media: Part I-finite element formulations," Journal of Energy Resources Technology, vol. 112, no. 1, pp. 1-9, 1990.

[17] J. Romero, M. G. Mack, and J. L. Elbel, "Theoretical model and numerical investigation of near-wellbore effects in hydraulic fracturing," in Proceedings of the SPE Annual Technical Conference and Exhibition, October 1995.
[18] H. Zhao, X. Wang, and Z. Liu, "Experimental investigation of hydraulic sand fracturing on fracture propagation under the influence of coal macrolithotypes in Hancheng block, China," Journal of Petroleum Science and Engineering, vol. 175, pp. 60-71, 2019.

[19] I. de-Pouplana and E. Oñate, "Finite element modelling of fracture propagation in saturated media using quasi-zerothickness interface elements," Computers and Geotechnics, vol. 96, pp. 103-117, 2018.

[20] R. G. Escobar, E. C. M. Sanchez, D. Roehl, and C. Romanel, "XFEM modeling of stress shadowing in multiple hydraulic fractures in multi-layered formations," Journal of Natural Gas Science and Engineering, vol. 70, Article ID 102950, 15 pages, 2019.

[21] H. Shimizu, S. Murata, and T. Ishida, "The distinct element analysis for hydraulic fracturing in hard rock considering fluid viscosity and particle size distribution," International Journal of Rock Mechanics and Mining Sciences, vol. 48, no. 5, pp. 712-727, 2011.

[22] L. Q. Choo, Z. Zhao, H. Chen, and Q. Tian, "Hydraulic fracturing modeling using the discontinuous deformation analysis (DDA) method," Computers and Geotechnics, vol. 76, pp. 12-22, 2016.

[23] C. Yao, J. F. Shao, Q. H. Jiang, and C. B. Zhou, "A new discrete method for modeling hydraulic fracturing in cohesive porous materials," Journal of Petroleum Science and Engineering, vol. 180, pp. 257-267, 2019.

[24] B. Paul, M. Faivre, P. Massin et al., “3D coupled HM-XFEM modeling with cohesive zone model and applications to non planar hydraulic fracture propagation and multiple hydraulic fractures interference," Computer Methods in Applied Mechanics and Engineering, vol. 342, pp. 321-353, 2018.

[25] Y. Feng, X. Li, and K. E. Gray, "Development of a 3D numerical model for quantifying fluid-driven interface debonding of an injector well," International Journal of Greenhouse Gas Control, vol. 62, pp. 76-90, 2017.

[26] H. Ouchi, J. T. Foster, and M. M. Sharma, "Effect of reservoir heterogeneity on the vertical migration of hydraulic fractures," Journal of Petroleum Science and Engineering, vol. 151, pp. 384-408, 2017.

[27] X. Weng, "Modeling of complex hydraulic fractures in naturally fractured formation," Journal of Unconventional Oil and Gas Resources, vol. 9, pp. 114-135, 2015.

[28] J. Adachi, E. Siebrits, A. Peirce, and J. Desroches, "Computer simulation of hydraulic fractures," International Journal of Rock Mechanics and Mining Sciences, vol. 44, no. 5, pp. 739-757, 2007.

[29] X. Li, Z. Feng, G. Han et al., "Breakdown pressure and fracture surface morphology of hydraulic fracturing in shale with $\mathrm{H} 2 \mathrm{O}, \mathrm{CO} 2$ and N 2," Geomechanics and Geophysics for Geo-Energy and Geo-Resources, vol. 2, no. 2, pp. 63-76, 2016.

[30] N. R. Warpinski, M. Mayerhofer, K. Agarwal, and J. Du, "Hydraulic-fracture geomechanics and microseismic-source mechanisms," SPE Journal, vol. 18, no. 4, pp. 766-780, 2013.

[31] S. I. Kaka, J. M. Reyes-Montes, A. Al-Shuhail, A. A. AlShuhail, and M. Jervis, "Analysis of microseismic events during a multistage hydraulic stimulation experiment at a shale gas reservoir," Petroleum Geoscience, vol. 23, no. 3, pp. 386-394, 2017.

[32] C. J. de Pater, M. P. Cleary, T. S. Quinn, D. T. Barr, D. E. Johnson, and L. Weijers, "Experimental verification of dimensional analysis for hydraulic fracturing," SPE Production \& Facilities, vol. 9, no. 4, pp. 230-238, 1994. 
[33] Y. Wang, H. Zhang, H. Lin, Y. Zhao, and Y. Liu, "Fracture behaviour of central-flawed rock plate under uniaxial compression," Theoretical and Applied Fracture Mechanics, vol. 106, p. 15, 2020.

[34] H. Lin, H. Yang, Y. Wang, Y. Zhao, and R. Cao, "Determination of the stress field and crack initiation angle of an open flaw tip under uniaxial compression," Theoretical and Applied Fracture Mechanics, vol. 104, p. 13, 2019.

[35] Y. Zhao, Y. Wang, W. Wang, L. Tang, Q. Liu, and G. Cheng, "Modeling of rheological fracture behavior of rock cracks subjected to hydraulic pressure and far field stresses," Theoretical and Applied Fracture Mechanics, vol. 101, pp. 59-66, 2019.

[36] Y. Zhao, Y. Wang, W. Wang, W. Wan, and J. Tang, “Testing study on crack propagation due to rheological fracture in quasi-brittle material under compression-shear or double torsional loading," Geotechnical and Geological Engineering, vol. 34, no. 5, pp. 1655-1667, 2016.

[37] Y. Zhao, Y. Wang, and L. Tang, "The compressive-shear fracture strength of rock containing water based on DrukerPrager failure criterion," Arabian Journal of Geosciences, vol. 12, p. 8, 2019.

[38] Y. Zhao, S. Luo, Y. Wang, W. Wang, L. Zhang, and W. Wan, "Numerical analysis of Karst water inrush and a criterion for establishing the width of water-resistant rock pillars," Mine Water and the Environment, vol. 36, no. 4, pp. 508-519, 2017.

[39] H. Lin, P. Cao, and Y. Wang, "Numerical simulation of a layered rock under triaxial compression," International Journal of Rock Mechanics and Mining Sciences, vol. 60, pp. 12-18, 2013.

[40] S. Xie, H. Lin, Y. Wang et al., "A statistical damage constitutive model considering whole joint shear deformation," International Journal of Damage Mechanics, vol. 29, no. 6, pp. 988-1008, 2020.

[41] C. Zhang, P. Zou, Y. Wang, T. Jiang, H. Lin, and P. Cao, “An elasto-visco-plastic model based on stress functions for deformation and damage of water-saturated rocks during the freeze-thaw process," Construction and Building Materials, vol. 250, p. 13, 2020.

[42] A. P. Bunger, R. G. Jeffrey, and E. Detournay, "Application of scaling laws to laboratory-scale hydraulic fractures," in Proceedings of the Alaska Rocks 2005, the 40th US Symposium on Rock Mechanics (USRMS), American Rock Mechanics Association, Anchorage, AK, USA, June 2005.

[43] N. Lamont and F. W. Jessen, "The effects of existing fractures in rocks on the extension of hydraulic fractures," Journal of Petroleum Technology, vol. 15, no. 2, pp. 203-209, 1963.

[44] W. G. P. Kumari, P. G. Ranjith, M. S. A. Perera et al., "Hydraulic fracturing under high temperature and pressure conditions with micro CT applications: geothermal energy from hot dry rocks," Fuel, vol. 230, pp. 138-154, 2018.

[45] C. Lin, J. He, X. Li, X. Wan, and B. Zheng, “An experimental investigation into the effects of the anisotropy of shale on hydraulic fracture propagation," Rock Mechanics and Rock Engineering, vol. 50, no. 3, pp. 543-554, 2017.

[46] S. H. Fallahzadeh, V. Rasouli, and M. Sarmadivaleh, "An investigation of hydraulic fracturing initiation and nearwellbore propagation from perforated boreholes in tight formations," Rock Mechanics and Rock Engineering, vol. 48, no. 2, pp. 573-584, 2015.

[47] M. Sarmadivaleh and V. Rasouli, "Test design and sample preparation procedure for experimental investigation of hydraulic fracturing interaction modes," Rock Mechanics and Rock Engineering, vol. 48, no. 1, pp. 93-105, 2015.
[48] H. Fatahi, M. M. Hossain, and M. Sarmadivaleh, "Numerical and experimental investigation of the interaction of natural and propagated hydraulic fracture," Journal of Natural Gas Science and Engineering, vol. 37, pp. 409-424, 2017.

[49] C. J. de Pater and L. J. L. Beugelsdijk, "Experiments and numerical simulation of hydraulic fracturing in naturally fractured rock,", in Proceedings of the Alaska Rocks 2005, the 40th US Symposium on Rock Mechanics (USRMS), American Rock Mechanics Association, Anchorage, AK, USA, June 2005.

[50] C. H. Yew and X. Weng, Mechanics of Hydraulic Fracturing, Gulf Professional Publishing, Houston, TX, USA, 2014.

[51] A. A. Daneshy, "Hydraulic fracture propagation in layered formations," Society of Petroleum Engineers Journal, vol. 18, no. 1, pp. 33-41, 1978.

[52] G. D. Anderson, "Effects of friction on hydraulic fracture growth near unbonded interfaces in rocks," Society of Petroleum Engineers Journal, vol. 21, no. 1, pp. 21-29, 1981.

[53] B. Gonçalves da Silva, B. Q. Li, Z. Moradian, J. T. Germaine, and H. H. Einstein, "Development of a test setup capable of producing hydraulic fracturing in the laboratory with image and acoustic emission monitoring," in Proceedings of the 49th US Rock Mechanics/Geomechanics Symposium, American Rock Mechanics Association, San Francisco, CA, USA, 2015.

[54] B. Gonçalves da Silva and H. Einstein, "Physical processes involved in the laboratory hydraulic fracturing of granite: visual observations and interpretation," Engineering Fracture Mechanics, vol. 191, pp. 125-142, 2018.

[55] B. Q. Li, B. Gonçalves da Silva, and H. Einstein, "Laboratory hydraulic fracturing of granite: acoustic emission observations and interpretation," Engineering Fracture Mechanics, vol. 209, pp. 200-220, 2019.

[56] C. Moreno, Y. Chitrala, C. Sondergeld, and C. Rai, "Laboratory studies of hydraulic fractures in tight sands at different applied stresses," in Proceedings of the SEG Technical Program Expanded Abstracts 2011, Society of Exploration Geophysicists, Houston, TX, USA, pp. 1550-1554, August 2011.

[57] M. Naoi, Y. Chen, K. Nishihara et al., "Monitoring hydraulically-induced fractures in the laboratory using acoustic emissions and the fluorescent method," International Journal of Rock Mechanics and Mining Sciences, vol. 104, pp. 53-63, 2018.

[58] K. Peng, J. Zhou, Q. Zou, and F. Yan, "Deformation characteristics of sandstones during cyclic loading and unloading with varying lower limits of stress under different confining pressures," International Journal of Fatigue, vol. 127, pp. 82-100, 2019.

[59] Y. Zhang, Y. Ma, Z. Hu et al., "An experimental investigation into the characteristics of hydraulic fracturing and fracture permeability after hydraulic fracturing in granite," Renewable Energy, vol. 140, pp. 615-624, 2019.

[60] D. Zhou, G. Zhang, P. Zhao, Y. Wang, and S. Xu, "Effects of post-instability induced by supercritical $\mathrm{CO}_{2}$ phase change on fracture dynamic propagation," Journal of Petroleum Science and Engineering, vol. 162, pp. 358-366, 2018.

[61] L. Zhuang, K. Y. Kim, S. G. Jung, M. Diaz, and K.-B. Min, "Effect of water infiltration, injection rate and anisotropy on hydraulic fracturing behavior of granite," Rock Mechanics and Rock Engineering, vol. 52, no. 2, pp. 575-589, 2019.

[62] R. Zhang, B. Hou, H. Han, M. Fan, and M. Chen, "Experimental investigation on fracture morphology in laminated 
shale formation by hydraulic fracturing," Journal of Petroleum Science and Engineering, vol. 177, pp. 442-451, 2019.

[63] L. Zhuang, K. Y. Kim, S. G. Jung et al., "Cyclic hydraulic fracturing of pocheon granite cores and its impact on breakdown pressure, acoustic emission amplitudes and injectivity," International Journal of Rock Mechanics and Mining Sciences, vol. 122, p. 9, 2019.

[64] S. Wang, D. Elsworth, and J. Liu, "Permeability evolution in fractured coal: the roles of fracture geometry and watercontent," International Journal of Coal Geology, vol. 87, no. 1, pp. 13-25, 2011.

[65] J. Chen, X. Li, and H. Cao, "Experimental investigation of coal-like materials for hydraulic fracturing based on fluidsolid interaction," Journal of Natural Gas Science and Engineering, vol. 69, p. 17, 2019.

[66] P. Tan, Y. Jin, B. Hou, X. Zheng, X. Guo, and J. Gao, "Experiments and analysis on hydraulic sand fracturing by an improved true tri-axial cell," Journal of Petroleum Science and Engineering, vol. 158, pp. 766-774, 2017.

[67] X. Ma, N. Li, C. Yin et al., "Hydraulic fracture propagation geometry and acoustic emission interpretation: a case study of Silurian Longmaxi formation shale in Sichuan Basin, SW China," Petroleum Exploration and Development, vol. 44, no. 6, pp. 1030-1037, 2017.

[68] C. J. de Pater, L. Weijers, M. Savic, K. H. A. A. Wolf, P. J. Van Den Hoek, and D. T. Barr, "Experimental study of nonlinear effects in hydraulic fracture propagation(includes associated papers 29225 and 29687 )," SPE Production \& Facilities, vol. 9, no. 04, pp. 239-246, 1994.

[69] T. Guo, Z. Rui, Z. Qu, and N. Qi, "Experimental study of directional propagation of hydraulic fracture guided by multi-radial slim holes," Journal of Petroleum Science and Engineering, vol. 166, pp. 592-601, 2018.

[70] S. Wu, T. Li, H. Ge, X. Wang, N. Li, and Y. Zou, "Sheartensile fractures in hydraulic fracturing network of layered shale," Journal of Petroleum Science and Engineering, vol. 183, p. 12, 2019.

[71] K. Peng, J. Zhou, Q. Zou, and X. Song, "Effect of loading frequency on the deformation behaviours of sandstones subjected to cyclic loads and its underlying mechanism," International Journal of Fatigue, vol. 131, p. 12, 2020.

[72] J. Zhou, M. Chen, Y. Jin, and G.-Q. Zhang, "Analysis of fracture propagation behavior and fracture geometry using a tri-axial fracturing system in naturally fractured reservoirs," International Journal of Rock Mechanics and Mining Sciences, vol. 45, no. 7, pp. 1143-1152, 2008.

[73] G.-Q. Zhang and T. Fan, "A high-stress tri-axial cell with pore pressure for measuring rock properties and simulating hydraulic fracturing," Measurement, vol. 49, pp. 236-245, 2014.

[74] L. J. L. Beugelsdijk, C. J. de Pater, and K. Sato, "Experimental hydraulic fracture propagation in a multi-fractured medium," in Proceedings of the SPE Asia Pacific Conference on Integrated Modelling for Asset Management, Society of Petroleum Engineers, Kuala Lumpur, Malaysia, March 2000.

[75] Z. Liu, M. Chen, and G. Zhang, "Analysis of the influence of a natural fracture network on hydraulic fracture propagation in carbonate formations," Rock Mechanics and Rock Engineering, vol. 47, no. 2, pp. 575-587, 2014.

[76] J. Hampton, M. Gutierrez, L. Matzar, D. Hu, and L. Frash, "Acoustic emission characterization of microcracking in laboratory-scale hydraulic fracturing tests," Journal of Rock Mechanics and Geotechnical Engineering, vol. 10, no. 5, pp. 805-817, 2018.
[77] Y. Li, J. Peng, C. Huang et al., "Multi-fractured stimulation technique of hydraulic fracturing assisted by the DTHhammer-induced impact fractures," Geothermics, vol. 82, pp. 63-72, 2019.

[78] Z. Bennour, T. Ishida, Y. Nagaya et al., "Crack extension in hydraulic fracturing of shale cores using viscous oil, water, and liquid carbon dioxide," Rock Mechanics and Rock Engineering, vol. 48, no. 4, pp. 1463-1473, 2015.

[79] Y. Zou, N. Li, X. Ma, S. Zhang, and S. Li, "Experimental study on the growth behavior of supercritical $\mathrm{CO}_{2}$-induced fractures in a layered tight sandstone formation," Journal of Natural Gas Science and Engineering, vol. 49, pp. 145-156, 2018.

[80] T. Guo, S. Zhang, Z. Qu, T. Zhou, Y. Xiao, and J. Gao, "Experimental study of hydraulic fracturing for shale by stimulated reservoir volume,” Fuel, vol. 128, pp. 373-380, 2014.

[81] Y. Xing, G. Zhang, T. Luo, Y. Jiang, and S. Ning, "Hydraulic fracturing in high-temperature granite characterized by acoustic emission," Journal of Petroleum Science and Engineering, vol. 178, pp. 475-484, 2019.

[82] B. Bohloli and C. J. de Pater, "Experimental study on hydraulic fracturing of soft rocks: influence of fluid rheology and confining stress," Journal of Petroleum Science and Engineering, vol. 53, no. 1-2, pp. 1-12, 2006.

[83] B. Hou, R. Zhang, Y. Zeng, W. Fu, Y. Muhadasi, and M. Chen, "Analysis of hydraulic fracture initiation and propagation in deep shale formation with high horizontal stress difference," Journal of Petroleum Science and Engineering, vol. 170, pp. 231-243, 2018.

[84] Z.-L. Zhou, G.-Q. Zhang, H.-R. Dong, Z.-B. Liu, and Y.-X. Nie, "Creating a network of hydraulic fractures by cyclic pumping," International Journal of Rock Mechanics and Mining Sciences, vol. 97, pp. 52-63, 2017.

[85] A. N. Dehghan, K. Goshtasbi, K. Ahangari, and Y. Jin, "Experimental investigation of hydraulic fracture propagation in fractured blocks," Bulletin of Engineering Geology and the Environment, vol. 74, no. 3, pp. 887-895, 2015.

[86] L. Weijers and C. J. de Pater, "Fracture reorientation in model tests," in Proceedings of the SPE Formation Damage Control Symposium, Society of Petroleum Engineers, Lafayette, LO, USA, 1992.

[87] H. Gu, X. Weng, J. B. Lund, M. G. Mack, U. Ganguly, and R. Suarez-Rivera, "Hydraulic fracture crossing natural fracture at nonorthogonal angles: a criterion and its validation," SPE Production \& Operations, vol. 27, no. 1, pp. 20-26, 2012.

[88] C. Zhang, H. Lin, C. Qiu, T. Jiang, and J. Zhang, "The effect of cross-section shape on deformation, damage and failure of rock-like materials under uniaxial compression from both a macro and micro viewpoint," International Journal of Damage Mechanics, pp. 1-24, 2020.

[89] C. Zhang, C. Pu, R. Cao, T. Jiang, and G. Huang, "The stability and roof-support optimization of roadways passing through unfavorable geological bodies using advanced detection and monitoring methods, among others, in the Sanmenxia Bauxite Mine in China's Henan Province," Bulletin of Engineering Geology and the Environment, vol. 78, pp. 5087-5099, 2019.

[90] H. Chen, X. Fan, H. Lai, Y. Xie, and Z. He, "Experimental and numerical study of granite blocks containing two side flaws and a tunnel-shaped opening," Theoretical and Applied Fracture Mechanics, vol. 104, p. 21, 2019. 
[91] P. Guo, X. Gong, and Y. Wang, "Displacement and force analyses of braced structure of deep excavation considering unsymmetrical surcharge effect," Computers and Geotechnics, vol. 113, p. 17, 2019.

[92] Y. Xu and P. Guo, "Disturbance evolution behavior of loess soil under triaxial compression," Advances in Civil Engineering, vol. 2020, Article ID 4160898, 14 pages, 2020.

[93] V. P. Nguyen, H. Lian, T. Rabczuk, and S. Bordas, "Modelling hydraulic fractures in porous media using flow cohesive interface elements," Engineering Geology, vol. 225, pp. 68-82, 2017.

[94] P. K. Rajmeny, U. K. Singh, and S. S. Rathore, "A new model to estimate rock mass strength accounting for the scale effect," International Journal of Rock Mechanics and Mining Sciences, vol. 41, no. 6, pp. 1013-1021, 2004.

[95] C. Scavia, "The effect of scale on rock fracture toughness: a fractal approach," Géotechnique, vol. 46, no. 4, pp. 683-693, 1996.

[96] Y.-C. Chiang, "The Poisson effect on the curved beam analysis," Structural Engineering and Mechanics, vol. 19, no. 6, pp. 707-720, 2005.

[97] L. Hu, A. Ghassemi, J. Pritchett, and S. Garg, "Characterization of laboratory-scale hydraulic fracturing for EGS," Geothermics, vol. 83, p. 14, 2020.

[98] Y. Chen, Y. Nagaya, and T. Ishida, "Observations of fractures induced by hydraulic fracturing in anisotropic granite," Rock Mechanics and Rock Engineering, vol. 48, no. 4, pp. 14551461, 2015.

[99] B. Zhang, J. Liu, S. G. Wang et al., "Impact of the distance between pre-existing fracture and wellbore on hydraulic fracture propagation," Journal of Natural Gas Science and Engineering, vol. 57, pp. 155-165, 2018.

[100] T.-G. Fan and G.-Q. Zhang, "Laboratory investigation of hydraulic fracture networks in formations with continuous orthogonal fractures," Energy, vol. 74, pp. 164-173, 2014.

[101] C. Jiang, B. Niu, G. Yin, D. Zhang, T. Yu, and P. Wang, "CTbased $3 \mathrm{D}$ reconstruction of the geometry and propagation of hydraulic fracturing in shale," Journal of Petroleum Science and Engineering, vol. 179, pp. 899-911, 2019.

[102] S. Heng, X. Liu, X. Li, X. Zhang, and C. Yang, "Experimental and numerical study on the non-planar propagation of hydraulic fractures in shale," Journal of Petroleum Science and Engineering, vol. 179, pp. 410-426, 2019.

[103] W. Cheng, Y. Jin, and M. Chen, "Reactivation mechanism of natural fractures by hydraulic fracturing in naturally fractured shale reservoirs," Journal of Natural Gas Science and Engineering, vol. 23, pp. 431-439, 2015.

[104] T. P. Lhomme, C. J. de Pater, and P. H. Helfferich, "Experimental study of hydraulic fracture initiation in Colton sandstone,", in Proceedings of the SPE/ISRM Rock Mechanics Conference, Society of Petroleum Engineers, Nancy, France, February 2002.

[105] L. Casas, J. L. Miskimins, A. Black, and S. Green, "Laboratory hydraulic fracturing test on a rock with artificial discontinuities," in Proceedings of the SPE Annual Technical Conference and Exhibition, Society of Petroleum Engineers, Houston, TX, USA, 2006.

[106] Y. Lou, G. Zhang, and X. Wang, "Study on fracture mechanism of hydraulic fracturing in sandstone by acoustic emission parameters," Procedia Engineering, vol. 191, pp. 291-298, 2017.

[107] C. Chen, H. Zhang, S. Liu et al., "Hydraulic fracturing in ice boreholes: theory and tests," Polar Science, vol. 19, pp. 40-48, 2019.
[108] R. Zhang, B. Hou, Q. Shan et al., "Hydraulic fracturing initiation and near-wellbore nonplanar propagation from horizontal perforated boreholes in tight formation," Journal of Natural Gas Science and Engineering, vol. 55, pp. 337-349, 2018.

[109] B. Liu, Y. Jin, and M. Chen, "Influence of vugs in fracturedvuggy carbonate reservoirs on hydraulic fracture propagation based on laboratory experiments," Journal of Structural Geology, vol. 124, pp. 143-150, 2019.

[110] B. Hou, R. Zhang, M. Chen, J. Kao, and X. Liu, "Investigation on acid fracturing treatment in limestone formation based on true tri-axial experiment," Fuel, vol. 235, pp. 473-484, 2019.

[111] F. Wu, R. Gao, Q. Zou, J. Chen, W. Liu, and K. Peng, "Longterm strength determination and nonlinear creep damage constitutive model of salt rock based on multistage creep test: implications for underground natural gas storage in salt cavern," Energy Science \& Engineering, vol. 8, no. 5, pp. 1592-1603, 2020.

[112] Q. Yin, G. Ma, H. Jing et al., "Hydraulic properties of 3D rough-walled fractures during shearing: an experimental study," Journal of Hydrology, vol. 555, pp. 169-184, 2017.

[113] K. Peng, H. Lv, F. Yan, Q. Zou, X. Song, and Z. Liu, "Effects of temperature on mechanical properties of granite under different fracture modes," Engineering Fracture Mechanics, vol. 226, Article ID 106838, 13 pages, 2020.

[114] Q. Yin, R. Liu, H. Jing, H. Su, L. Yu, and L. He, "Experimental study of nonlinear flow behaviors through fractured rock samples after high-temperature exposure," Rock Mechanics and Rock Engineering, vol. 52, no. 9, pp. 2963-2983, 2019.

[115] B. Hou, C. Diao, and D. Li, "An experimental investigation of geomechanical properties of deep tight gas reservoirs," Journal of Natural Gas Science and Engineering, vol. 47, pp. 22-33, 2017.

[116] Y. Zhao, L. Zhang, J. Liao, W. Wang, Q. Liu, and L. Tang, "Experimental study of fracture toughness and subcritical crack growth of three rocks under different environments," International Journal of Geomechanics, vol. 20, no. 8, p. 15, 2020.

[117] K. Hayashi and T. Ito, "In situ stress measurement by hydraulic fracturing at the Kamaishi mine," International Journal of Rock Mechanics and Mining Sciences \& Geomechanics Abstracts, vol. 30, no. 7, pp. 951-957, 1993.

[118] N. R. Warpinski and L. W. Teufel, "Influence of geologic discontinuities on hydraulic fracture propagation (includes associated papers 17011 and 17074)," Journal of Petroleum Technology, vol. 39, no. 2, pp. 209-220, 1987.

[119] J. Zhou, Y. Jin, and M. Chen, "Experimental investigation of hydraulic fracturing in random naturally fractured blocks," International Journal of Rock Mechanics and Mining Sciences, vol. 47, no. 7, pp. 1193-1199, 2010.

[120] W. Wang, J. E. Olson, M. Prodanović, and R. A. Schultz, "Interaction between cemented natural fractures and hydraulic fractures assessed by experiments and numerical simulations," Journal of Petroleum Science and Engineering, vol. 167 , pp. 506-516, 2018. 